\title{
Constitutive "Light" Adaptation in Rods from G90D Rhodopsin: A Mechanism for Human Congenital Nightblindness without Rod Cell Loss
}

\author{
Paul A. Sieving, ${ }^{1}$ Michael L. Fowler, ${ }^{1}$ Ronald A. Bush, ${ }^{1}$ Shigeki Machida, ${ }^{1}$ Peter D. Calvert, ${ }^{2}$ Daniel G. Green, ${ }^{1}$ \\ Clint L. Makino, ${ }^{2}$ and Christina L. McHenry ${ }^{1}$ \\ ${ }^{1}$ Department of Ophthalmology and Visual Sciences, University of Michigan, Ann Arbor, Michigan 48105, and \\ 2Department of Ophthalmology, Massachusetts Eye and Ear Infirmary, Harvard Medical School, Boston, \\ Massachusetts 02114
}

A dominant form of human congenital nightblindness is caused by a gly90 $\rightarrow$ asp (G90D) mutation in rhodopsin. G90D has been shown to activate the phototransduction cascade in the absence of light in vitro. Such constitutive activity of G90D rhodopsin in vivo would desensitize rod photoreceptors and lead to nightblindness. In contrast, other rhodopsin mutations typically give rise to nightblindness by causing rod cell death. Thus, the proposed desensitization without rod degeneration would be a novel mechanism for this disorder. To explore this possibility, we induced mice to express G90D opsin in their rods and then examined rod function and morphology, after first crossing the transgenic animals with rhodopsin knock-out mice to obtain appropriate levels of opsin expression. The G90D mouse opsin bound the chromophore and formed a bleachable visual pigment with $\lambda_{\max }$ of $492 \mathrm{~nm}$ that supported rod photoresponses. $(\mathrm{G}+/-, \mathrm{R}+/-)$ retinas, heterozygous for both G90D and wildtype (WT) rhodopsin, possessed normal numbers of photoreceptors and had a normal rhodopsin complement but exhibited considerable loss of rod sensitivity as measured electroretinographically. The rod photoresponses were desensitized, and the response time to peak was faster than in $(R+/-)$ animals. An equivalent desensitization resulted by exposing WT retinas to a background light producing 82 photoisomerizations rod $^{-1}$ $\mathrm{sec}^{-1}$, suggesting that G90D rods in darkness act as if they are partially "light-adapted." Adding a second G90D allele gave $(\mathrm{G}+/+, \mathrm{R}+/-)$ animals that exhibited a further increase of equivalent background light level but had no rod cell loss by 24 weeks of age. $(\mathrm{G}+/+, \mathrm{R}-/-)$ retinas that express only the mutant rhodopsin develop normal rod outer segments and show minimal rod cell loss even at 1 year of age. We conclude that G90D is constitutively active in mouse rods in vivo but that it does not cause significant rod degeneration. Instead, G90D desensitizes rods by a process equivalent to light adaptation.

Key words: constitutive activity; rhodopsin; light adaptation; retinal degeneration; rod photoreceptor; photoresponse; congenital nightblindness; transgenic mouse
Night vision is initiated when a rod photoreceptor absorbs a single photon (Hecht et al., 1942). Photon absorption causes a conformational change in the light-sensitive rhodopsin molecule and triggers the phototransduction cascade. The remarkable ability of the visual system to detect single photons requires that rhodopsin remains quiescent in the dark. Indeed, the half-life for the spontaneous activation of rhodopsin is $\sim 400$ years. However, because each rod contains $10^{8}$ rhodopsin molecules, thermal activation results in spontaneous bumps that resemble singlephoton events every 100-200 sec in rods maintained in the dark (Baylor et al., 1984). Rod dark noise measurements indicate that

Received March 8, 2001; revised May 11, 2001; accepted May 21, 2001.

This work was supported by National Institutes of Health Grants EY00379, EY06094, and EY07003-CORE; the Foundation Fighting Blindness (Hunt Valley, MD); Research to Prevent Blindness (P.A.S., D.G.G., C.L.M.); and the E. Mathilda Ziegler Foundation for the Blind, Inc. (C.L.M.). We thank Takeshi Sugawara, Eve Bingham, Natalia Kapousta-Bruneau, Bradley Nelson, and Austra Liepa for technical assistance. Jeff Jamison implemented the rhodopsin spectra curve-fitting program in Matlab. Dr. Julia Richards gave advice on transgene construction. Dr. Peter Humphries provided the rhodopsin knock-out mice. Rod photoreceptor single unit recordings were performed by P.D.C. and C.L.M. in the laboratory of Dr. Denis Baylor. We thank Drs. Carter Cornwall and David Cameron for discussions about the spectral properties of G90D rhodopsin and Drs. John Lisman and Gordon Fain for discussions regarding constitutively active rhodopsin mutations.

Correspondence should be addressed to Dr. Paul A. Sieving, Center for Retinal and Macular Degeneration, The W. K. Kellogg Eye Center, University of Michigan, 1000 Wall Street, Ann Arbor, MI 48105. E-mail: psieving@umich.edu.

Copyright (C) 2001 Society for Neuroscience $0270-6474 / 01 / 215449-12 \$ 15.00 / 0$ rod noise, generated from spontaneous activity of rhodopsin, limits behavioral sensitivity and sets the ultimate limit for absolute sensitivity of night vision (Baylor et al., 1984; Aho et al., 1988). If rhodopsin thermal activity were increased only slightly (Barlow, 1988) or if a genetic mutation resulted in constitutively active rhodopsin (Rao et al., 1994), the false light signals that are generated within the rod would compete with dim external stimuli and desensitize night vision.

We previously reported on a human pedigree with congenital nightblindness that cosegregated in autosomal dominant fashion with a G90D rhodopsin mutation (Sieving et al., 1995). More than 80 other rhodopsin mutations cause human autosomal dominant retinitis pigmentosa, in which nightblindness results from rod cell death (Berson, 1993). The G90D disease was unusual, however, in that the retinas clinically appeared to be minimally affected and the condition was nearly nonprogressive, suggesting that rods were not being lost with age. Furthermore, the rhodopsin density was measured in one G90D-affected subject using in vivo fundus reflection densitometry and was normal, indicating preservation of photon capture. The reduced photon capture associated with even a $50 \%$ reduction in rhodopsin density would elevate visual perceptual thresholds only $0.3 \log$ unit, far less than the $3 \log$ unit loss experienced by G90D subjects. The G90D mutation lies within the opsin pocket opposite to the lys-296 Schiff-base attachment of the 11-cis-retinal chromophore. We proposed that the 
G90D mutation destabilized the attachment, leading to endogenous signaling noise that physiologically desensitized the rods without causing significant cell death. G90D rhodopsin was subsequently shown by biochemical assay to activate transducin independent of light (Rao et al., 1994), termed "constitutive activation" (Robinson et al., 1992).

We undertook this study to learn whether G90D expression in vivo impaired rod function without causing rod cell loss. Transgenic approaches have previously been used to study the effects of other rhodopsin mutants that cause retinitis pigmentosa in humans. For example, the $\mathrm{P} 23 \mathrm{H}$ rhodopsin transgenic mouse (Olsson et al., 1992; Naash et al., 1993) and rat (Steinberg et al., 1996) successfully reproduced the rod degeneration and corresponding rod functional impairment (Machida et al., 2000) present in human $\mathrm{P} 23 \mathrm{H}$ rhodopsin patients (Berson et al., 1991). Transgenic mice carrying other human retinitis pigmentosa rhodopsin mutations also showed progressive rod degeneration (Huang et al., 1993; Li et al., 1994, 1996; Sung et al., 1994; Chen et al., 1995). Interestingly, a transgenic mouse carrying K296E rhodopsin, which exhibits biochemical "constitutive activity" in vitro (Robinson et al., 1992), failed to show physiological light-adaptation effects in vivo by electroretinogram (ERG) recordings (Li et al., 1995). Instead, ERG losses in K296E mice correlated with the degree of photoreceptor degeneration. Thus, our expectation that mutant G90D rhodopsin in the mouse retina might demonstrate congenital nightblindness without rod cell loss was novel.

\section{MATERIALS AND METHODS}

Generation of G90D transgenic mice. Studies were conducted according to principles of the Society for Neuroscience, using protocols reviewed at the University of Michigan. A $15 \mathrm{~kb}$ rhodopsin genomic clone was isolated from an adult BALB/c mouse liver genomic lambda library (Clontech, Palo Alto, CA). The clone contained $5 \mathrm{~kb}$ upstream from exon 1 to direct expression specifically to the rod photoreceptors (Lem et al., 1991; Zack et al., 1991; Quiambao et al., 1997). This was cloned into pGEM-5Zf(-) (Promega, Madison, WI) and designated pRHO-5. An Eco-RI fragment containing the coding sequence was subcloned into pBS2SK $(-)$ (Stratagene, La Jolla, CA), and two separate site-directed mutagenesis procedures were performed (Transformer Site-Directed Mutagenesis Kit, Clontech). The G90D mutation was made using the oligonucleotide TGGTGGTGAAGTCTCCGAAGACCATG. A second, conservative mutagenesis (A337V) substituted a valine, found in normal human rhodopsin, for the alanine in mouse rhodopsin. Transgene expression could be tracked then using the 3A6 rhodopsin antibody that recognizes human V337 opsin but not mouse A337 opsin (Al-Ubaidi et al., 1990; Olsson et al., 1992). The A337V change lies distant from known functional opsin domains, and expression of human opsin (which contains the valine residue at codon 337$)$ on mouse $(\mathrm{R}-/-)$ background has no effect on ERG b-wave threshold or amplitude-intensity relations (McNally et al., 1999). The transgene construct was spliced together from the corresponding EcoRI-HindIII fragment of both constructs, cloned back into pRHO-5, and checked for normal sequence across the splice regions. The rhodopsin construct was injected into fertilized eggs from a C57BL/6 cross DBA mouse mating and implanted into pseudopregnant females. Sixty-three founder mice were produced, and selected lines were propagated by mating with C57BL/6 mice (Jackson Laboratories, Bar Harbor, ME). Animals were housed in controlled lighting measuring 5 lux at cage level on a $12 \mathrm{hr}$ light/dark cycle.

Genotyping. DNA was extracted from mouse tail. The transgene was identified on WT $(\mathrm{R}+/+)$ rhodopsin background by PCR amplification using primers AAGCAGCCTTGGTCTCTGTC (forward) and GTCTCTCTGCTCATACCTCC (reverse), which give a 435 bp fragment of exon 1 across the G90D site. Because the G90D mutation destroys the Tfi-I site in this fragment, overnight restriction with Tfi-I enzyme reduces the WT fragment to a $327 \mathrm{bp}$ fragment but leaves the 435 bp transgenic fragment uncut. Genomic copy number relative to WT was estimated by comparing band densities after Tfi-I restriction. Typing for the A337V transgene site was by PCR amplification using exon 5 primers TGTATGCTCACCACGCTGTGC (forward) and CTTGT-
CATGTTCCTGATAGACAAGC (reverse), which give a 394 bp band. Restricting with Aci-I enzyme gave $23,39,47$, and 285 bp fragments for WT and 23, 39, 47, 285, and $324 \mathrm{bp}$ fragments for the transgene. Genotyping of mice with or without the G90D transgene on hemizygous $(\mathrm{R}+/-)$ or homozygous $(\mathrm{R}-/-)$ background was done using long-range PCR across the G90D site in exon 1 and the neomycin knock-out cassette in exon 2 using primers TTTATGTGCCCTTCTCCAACGTCACAGGCGT (forward, 5' of codon 90) and TGATCCAGGTGAAGACCACACCCATGATAGC (reverse, $3^{\prime}$ of the PolII:Neomycin cassette). The G90D and WT alleles both give a 1950 bp product that was restricted with Tfi-I to give three bands at 476/617/820 bp for the G90D transgene, whereas WT gives four bands at 244/476/576/617 bp. The rhodopsin knock-out allele contains an additional $3100 \mathrm{bp}$ of the neomycin cassette, so long-range PCR gives a 5050 bp band.

$m R N A$. Mice were killed with sodium pentobarbital overdose $(300$ $\mathrm{mg} / \mathrm{kg}$, i.p.); the retinas were removed and quickly frozen in liquid nitrogen. mRNA was prepared using a Micro-Fast Track mRNA Isolation Kit (Invitrogen, San Diego, CA). First-strand synthesis was performed using reverse transcriptase (RT)-PCR primers in exon 1 surrounding codon 90: AAGCAGCCTTGGTCTCTGTC (forward) and GTCTCTCTGCTCATACCTCC (reverse). Restricting the RT-PCR product to completion overnight with Tfi-I cleaved the WT cDNA to give a $327 \mathrm{bp}$ band but left the $435 \mathrm{bp}$ G90D band intact. Band densities were determined by optical scanning, and the relative densities, corrected for molecular weight, gave the relative amounts of G90D and WT mRNA. In line 202 animals, the G90D/WT mRNA ratio in $(\mathrm{G}+/-, \mathrm{R}+/+)$ mice was 0.82 ( 0.80 and 0.84 , in two different animals), equivalent to a 1.64 ratio of G90D per single WT allele. A similar result was obtained from two $(\mathrm{G}+/-, \mathrm{R}+/-)$ mice that gave an mRNA ratio for transgene: WT of 1.49 (1.43 and 1.56, in two different animals).

Whole retina rhodopsin assay. Procedures were performed under dim red or infrared light using infrared goggles. Mice were dark-adapted overnight for $12 \mathrm{hr}$ and then killed by sodium pentobarbital overdose (300 $\mathrm{mg} / \mathrm{kg}$, i.p.). Retinas were removed through a slit in the cornea (Fulton et al., 1982) and homogenized in $0.5 \mathrm{ml}$ of $1 \%$ emulphogene (Williams et al., 1998) in $1.5 \mathrm{ml}$ Eppendorf tubes. The tubes were kept in the dark for $1 \mathrm{hr}$ at $4^{\circ} \mathrm{C}$ and centrifuged; the absorbance of the supernatant was determined between 400 and $700 \mathrm{~nm}$ (Lambda 20 UV-Visible Spectrophotometer; PerkinElmer Life Sciences, Norwalk, CT). Rhodopsin was bleached completely by exposure to bright, white fluorescent light for 10 min and then rescanned to obtain postbleach spectra. Spectra were zeroed at $700 \mathrm{~nm}$, and difference spectra were obtained by subtracting postbleach from prebleach spectra. Rhodopsin quantity was calculated in nanomoles per eye using absorbance at the $\lambda_{\max }$ of the difference spectra and extinction coefficients of $42,700 \mathrm{M}^{-1} \mathrm{~cm}^{-1}$ for WT rhodopsin and $37,000 \mathrm{M}^{-1} \mathrm{~cm}^{-1}$ for G90D rhodopsin (Zvyaga et al., 1996). $\lambda_{\max }$ values of the difference spectra were obtained by least-squares fitting of a pigment nomogram in polynomial form (Dawis, 1981). Fits generally extended across a range of 450 or 470 to $575 \mathrm{~nm}$.

In retinas expressing a mixture of G90D and WT rhodopsins, hydroxylamine $\left(\mathrm{NH}_{2} \mathrm{OH}\right)$ was added to the extracted rhodopsin to determine the separate quantities of G90D and WT rhodopsin. Hydroxylamine does not react with unbleached WT rhodopsin, but with bleached WT pigment it forms stable retinal oxime with $\lambda_{\max }=367 \mathrm{~nm}$ (Crescitelli, 1956). The rhodopsin Schiff base becomes accessible to hydroxylamine only after the Glu113 counterion is at least partially protonated during bleaching (Sakmar et al., 1989; Zvyaga et al., 1993). However, hydroxylamine reacts with unbleached G90D pigment with a decay half-time of $2.7 \mathrm{~min}$ at $\mathrm{pH} 8.0$ and $15^{\circ} \mathrm{C}$ (Zvyaga et al., 1996). Retinas were washed in $10-12 \mathrm{ml}$ of distilled $\mathrm{H}_{2} \mathrm{O}$ to remove blood contaminants that react with hydroxylamine and then were extracted overnight in $0.5 \%$ dodecyl maltoside at $4^{\circ} \mathrm{C}$ in Tris maleate, $\mathrm{pH}$ 6-8 (Zvyaga et al., 1994). Absorbance of the extract was scanned between 400 and $700 \mathrm{~nm}$ before and after adding $\mathrm{NH}_{2} \mathrm{OH}$ to the cuvette, for a final concentration of $100 \mathrm{~mm}$, and then again after incubating for $10 \mathrm{~min}$ in the dark at room temperature. Then, the extract was bleached completely by exposure to white fluorescent light for $10 \mathrm{~min}$, and the absorbance was scanned a final time. Difference spectra for G90D absorbance were obtained by subtracting the spectrum after $\mathrm{NH}_{2} \mathrm{OH}$ from the spectrum before, both in darkness. WT absorbance was obtained by subtracting the light-bleached spectrum from the spectrum after $\mathrm{NH}_{2} \mathrm{OH}$ treatment but before light exposure. We verified experimentally that adding hydroxylamine did not change the absorbance values of WT rhodopsin. Comparisons of spectra from WT retinas with and without hydroxylamine showed no change in spectral bandwidth or $\lambda_{\max }$, indicating that the contribution from the 
hydroxylamine-sensitive cone pigments was not detectable and that any contribution of the retinal oxime product to the absorbance at the peak of the difference spectra was minor. Previous work indicated that for a difference spectrum with a peak near $490 \mathrm{~nm}$, retinal oxime changes $\lambda_{\max }$ by $<0.2 \mathrm{~nm}$ (Knowles and Dartnall, 1977).

Histology. Eyes were removed and fixed overnight at $4{ }^{\circ} \mathrm{C}$ in $4 \%$ paraformaldehyde and $2.5 \%$ glutaraldehyde in $0.1 \mathrm{~m}$ cacodylate buffer. The globes were trimmed, post-fixed in $1 \%$ osmium for $1 \mathrm{hr}$, and embedded in epon for light microscopy. Sections $(1 \mu \mathrm{m}$ thick) were cut along the vertical meridian passing through the optic nerve and stained with toluidine blue. Quantitative comparisons of photoreceptor cell numbers were made by counting the number of nuclei across the outer nuclear layer (ONL) width (LaVail et al., 1999; Sugawara et al., 2000). These measurements were made at $200 \mu \mathrm{m}$ intervals along 3600-4000 $\mu \mathrm{m}$ expanses of the retina under $20 \times$ magnification with a Zeiss optical microscope. Retinal thickness is erratic at the margins near the ora serrata, and these positions were not included. Thickness of the rod outer segment (ROS) and rod inner segment (RIS) layers were measured.

Immunohistochemistry was performed using the 3A6 and 1D4 antibodies (gift of Dr. Robert Molday, University of British Columbia, Vancouver, Canada). 3A6 conjugates with human opsin containing V337 (MacKenzie et al., 1984; Nathans and Hogness, 1984) but not with mouse A337 opsin (Al-Ubaidi et al., 1990; Olsson et al., 1992), and consequently, the $3 \mathrm{~A} 6$ antibody recognizes the G90D/A337V transgene product but not WT mouse opsin. The 1D4 antibody was developed against an epitope at 341-348 for bovine opsin (Molday and MacKenzie, 1983; MacKenzie et al., 1984) and recognizes both mouse WT A337 and the transgene 337V opsin (Olsson et al., 1992). Eyes were fixed overnight in $4 \%$ paraformaldehyde in $0.1 \mathrm{M}$ phosphate buffer at $4^{\circ} \mathrm{C}$, rinsed in $0.1 \mathrm{M}$ phosphate buffer, trimmed, and cryoprotected in increasing concentrations of sucrose in buffer. They were frozen in OCT that was diluted 1:2 in $20 \%$ sucrose/buffer for cryostat sectioning. Sections $(10 \mu \mathrm{m}$ thick $)$ were taken along the vertical meridian and mounted on poly-L-lysine coated slides. Nonspecific antibody binding was blocked by incubating sections for $1 \mathrm{hr}$ with $20 \%$ normal goat serum (NGS) in $0.25 \%$ Triton $\mathrm{X}-100$ and $0.1 \mathrm{M}$ PBS. Then, sections were incubated for $2 \mathrm{hr}$ in primary antibody diluted 1:10 for the rhodopsin 1D4 antibody or 1:50 for the rhodopsin $3 \mathrm{~A} 6$ antibody in PBS, $0.25 \%$ Triton X-100, and $2 \%$ NGS. Sections were washed and incubated for $1 \mathrm{hr}$ in tetramethylrhodamine isothiocyanate-conjugated goat anti-mouse IgG (Sigma, St. Louis, MO) that was diluted 1:64. Sections were final-washed, coverslipped, and photographed.

$E R G$ recordings in vivo. Mice were dark adapted for $12 \mathrm{hr}$, anesthetized with ketamine $(75 \mathrm{mg} / \mathrm{kg}$, i.m.) and xylazine $(13.6 \mathrm{mg} / \mathrm{kg}$, i.m.), and prepared under dim red light of $<0.01$ scotopic $\mathrm{cd} / \mathrm{m}^{2}$. Pupils were dilated with topical $0.05 \%$ phenylepherine $\mathrm{HCl}$ and $0.05 \%$ atropine. Body temperature was maintained on a warming block at $38^{\circ} \mathrm{C}$. A chlorided silver wire loop electrode was held on the cornea with a drop of methylcellulose. The differential electrode was a second loop placed beneath the upper eyelid; a subcutaneous wire on the forehead was the neutral electrode. Ganzfeld white light illumination was provided by a quartz-halogen lamp $\left(2800^{\circ} \mathrm{K}\right.$ color temperature $)$ that had unattenuated intensity of $130 \mathrm{~cd} / \mathrm{m}^{2}$. Electronic shutters controlled exposure duration that was nominally $50 \mathrm{msec}$. Interstimulus interval was $50 \mathrm{sec}$ for dim stimuli near threshold, and single traces were collected for intensities of the highest $2 \log$ units. Responses were amplified at $0.1-1000 \mathrm{~Hz}$ and computer averaged. Cone-driven responses were isolated by light adapting the animals with a $35 \mathrm{~cd} / \mathrm{m}^{2}$ full-field white background for $20 \mathrm{~min}$ before photopic recordings. Stimulus luminances in Table 3 are given in photopic candela seconds per square meter. These can be converted to scotopic units by adding $0.143 \log$ units for the $2800^{\circ} \mathrm{K}$ color source (Wyszecki and Stiles, 1982, their Table 2.4.4). We previously measured the increment threshold function of the WT mouse rod-driven b-wave and specified the background in photopic candela per square meter (Toda et al., 1999). We converted the photometric intensities to physiological quantal fluxes for the murine eye, following Lyubarsky and Pugh (1996) and Pugh (1998) and recognizing that $1 \mathrm{~cd} / \mathrm{m}^{2}=\pi$ lux for an extended Ganzfeld source. Transmissivity of the rodent lens (Gorgels and van Norren, 1992) is $\sim 1.6$ times greater than the human lens (Wyszecki and Stiles, their Table 2.4.6) for $\lambda=500 \mathrm{~nm}$. Using these factors in the conversion schema above, an ERG Ganzfeld stimulus of $2800^{\circ} \mathrm{K}$ with surface luminance of $1 \mathrm{~cd} / \mathrm{m}^{2}$ (at $\lambda=500 \mathrm{~nm}$ ) yields 2575 photoisomerizations $\operatorname{rod}^{-1} \mathrm{sec}^{-1}\left(\mathrm{Rh}^{*} \operatorname{rod}^{-1} \mathrm{sec}^{-1}\right)$ for the mouse.

Rod photovoltage recording from isolated retina. Animals were dark adapted for $12 \mathrm{hr}$ and prepared under dim infrared illumination. An animal was deeply anesthetized with sodium pentobarbital, decapitated, and enucleated. The globe was hemisected near the ora serrata and placed in Ringer's solution at room temperature; the retina was gently detached. A small piece of retina was placed receptor side up on Millipore filter in the recording chamber and bathed in Ringer's solution consisting of (in mM): $\mathrm{NaCl}, 110 ; \mathrm{KCl}, 5 ; \mathrm{Na}_{2} \mathrm{HPO}_{4}, 0.8 ; \mathrm{NaH}_{2} \mathrm{PO}_{4}, 0.1$; $\mathrm{NaHCO}_{3}, 30 ; \mathrm{MgSO}_{4}, 1 ; \mathrm{CaCl}_{2}, 1.8$; glucose, 22; glutamine, 0.25. The solution was warmed to $36-37^{\circ} \mathrm{C}$ and bubbled with a $95 \% \mathrm{O}_{2} / 5 \% \mathrm{CO}_{2}$ mixture, which maintained the $\mathrm{pH}$ between 7.45 and 7.55. Recordings were performed in a light-tight Faraday cage. Monochromatic stimuli of $500 \mathrm{~nm}(10 \mathrm{~nm}$ HBW $)$ were generated by a photoflash of $<1 \mathrm{msec}$ duration. Intensity was controlled with neutral density filters. The $500 \mathrm{~nm}$ photon flux of the flash was determined by physiological comparison of the b-wave intensity-response function that was elicited by a second light source calibrated using a radiometric detector (model S370; UDT Instruments, Orlando, FL). Responses were amplified at $0-400 \mathrm{~Hz}$, digitized at $1000 \mathrm{kHz}$, and stored. Photovoltage measurements were made with a pair of saline-filled 5-25 Mohm glass microelectrodes that were positioned across the photoreceptor layer by micromanipulators. The numbers of photoisomerizations per rod were calculated, assuming a quantum efficiency of bleaching of 0.5 , a pigment density of 0.3 (i.e., a $50 \%$ absorption probability), and a rod cross-sectional area of $2.3 \mu \mathrm{m}^{2}$ [for additional details, see Green and Kapousta-Bruneau (1999a,b)].

Single unit rod suction electrode recordings. A limited set of recordings of light-induced changes in ROS current of single rods was made using suction electrodes as described in Sung et al. (1994). After dark adapting a mouse for at least $12 \mathrm{hr}$, we removed and minced its retinas. Samples were placed into an experimental chamber and perfused continuously with an enriched Locke's solution at $35-37^{\circ} \mathrm{C}$. The outer segments of single rods were drawn into a suction electrode, and the responses to brief flashes were recorded with a current-to-voltage converter (Axopatch 200; Axon Instruments, Foster City, CA). The transgenic G90D mice were from founder 202 and were expressing mutant opsin on a background of two normal WT rhodopsin alleles $(\mathrm{G}+/-, \mathrm{R}+/+)$. These were 19- to 20-week-old animals (animals 491 and 488, line 202). Two WT $(\mathrm{R}+/+)$ littermates (5-6 weeks of age) were also studied, and results from the control mice were similar to those reported earlier for rods from C57BL/6 and C57BL/6 × DBA mice (Raport et al., 1994).

Statistical treatment. Because most measurements were made across three to five different genotypes, with the possibility of multiple pair-wise comparisons, the analysis was performed by one-way ANOVA with the Tukey post-test to detect significant differences between statistically appropriate pairs within each group.

\section{RESULTS \\ Preliminary studies of G90D on $(\mathrm{R}+/+)$ genetic background}

We created a transgenic mouse expressing G90D rhodopsin in the rods and then bred the transgene into the hemizygous and homozygous rhodopsin knock-out background. We were interested in two questions. Does expression of G90D rhodopsin decrease rod sensitivity to photic stimulation, and is the desensitization independent of rod cell death? These questions were approached by histological examination of the retinas and from physiological recordings of the light responses.

The first G90D transgenic animals expressed the mutant opsin on a WT $(\mathrm{R}+/+)$ genetic background. Founder mice were screened by ERG recordings to search for animals that showed a loss of sensitivity, and lines were developed from founders 116 and 202. These two lines both expressed a single G90D allele on a WT background $(\mathrm{G}+/-, \mathrm{R}+/+)$, and both showed $>1 \log$ unit elevation of the dark-adapted $b$-wave threshold. In histological sections of line 116 retinas at 8 weeks, the ONL, which is made up of photoreceptor nuclei, was reduced in thickness, and the rod outer segments ROSs appeared to be disrupted. Genomic Southern blot analysis indicated that line 116 carried a transgene copy number two to three times greater than line 202. Because rod degeneration can result from excessive expression of even wildtype opsin (Olsson et al., 1992), we would not be able to sort out 
rod deterioration caused by high transgene copy number for other effects, and we did not examine line 116 animals further.

In line 202 animals, by contrast, the $(\mathrm{G}+/-, \mathrm{R}+/+)$ retinas showed minimal anatomical changes at 8 weeks, and the rhodopsin content was only $\sim 0.1 \log$ unit lower than in WT C57BL/6 mice. It was clear that the ERG sensitivity loss in these line 202 animals was disproportionate to the decrease in photon catch.

Single rods from a few animals of line 202 were studied by suction electrode recording and showed reduced flash sensitivity. For WT rods, the flash strength at $500 \mathrm{~nm}$ required to produce half-maximum responses, $\mathrm{i}_{0}$, was $54 \pm 16$ photons $\mu \mathrm{m}^{-2}$ (mean \pm $\mathrm{SD}, n=7)$. The sensitivity of $(\mathrm{G}+/-, \mathrm{R}+/+)$ rods was depressed and required higher flash intensity of $107 \pm 32$ photons $\mu \mathrm{m}^{-2}$ $(n=7 ; p<0.002)$ to reach half-maximum responses. Therefore, at least some of the defects in the ERG were traced directly to functional changes in rod photoreceptors. The flash response onset was also faster in transgenic rods. For dim flashes, the time to peak for WT was $140 \pm 17 \mathrm{msec}(n=7)$, and for the G90D transgenics, $103 \pm 10 \mathrm{msec}(n=5 ; p<0.001)$. For half maximal responses, the time to peak for WT was $128 \pm 11 \mathrm{msec}(n=6)$, whereas this was faster for transgenic rods at $99 \pm 11 \mathrm{msec}(n=$ $5 ; p<0.02)$, consistent with a light adaptation effect.

\section{G90D on ( $R+/-)$ genetic background}

In an attempt to eliminate overexpression of rhodopsin as contributing to rod degeneration and to match the genomic constitution of WT and G90D rhodopsin present in the human condition more closely, we crossed the 202 line with rhodopsin knock-out mice (Humphries et al., 1997). We obtained a stable line of mice carrying one G90D allele on a background of a single WT rhodopsin allele $(\mathrm{G}+/-, \mathrm{R}+/-)$. In terms of the expression levels of WT and G90D rhodopsin, $(\mathrm{G}+/-, \mathrm{R}+/-)$ mice roughly corresponded to the autosomal dominant trait in the G90D human family. Both the 202 line and the knock-out animals were propagated by mating with $\mathrm{C} 57 \mathrm{BL} / 6$ mice, and by the time the final histology and ERG analyses were performed, these mice were primarily in the C57BL/6 background.

Because the allele number of both the transgene and WT gene could be manipulated independently, there were several different possible genotypes that one could compare. On the expectation (subsequently borne out) that histological differences would be minimal between $(\mathrm{G}+/-, \mathrm{R}+/-)$ and $(\mathrm{R}+/-)$, we compared littermates with these genotypes that were obtained from breeding $(\mathrm{G}+/-, \mathrm{R}+/+)$ with $(\mathrm{R}-/-)$ to see whether the presence of G90D would affect ERG sensitivity.

\section{Histology}

Mice expressing the G90D transgene on the heterozygous WT background, $(\mathrm{G}+/-, \mathrm{R}+/-)$, showed good preservation of photoreceptors when compared with $(\mathrm{R}+/-)$ littermates even at 30 weeks (Fig. 1). G90D opsin expression in the $(\mathrm{G}+/-, \mathrm{R}+/-)$ retina and not in the $(\mathrm{R}+/-)$ retina was demonstrated by using the $3 \mathrm{~A} 6$ antibody that recognizes the $337 \mathrm{~V}$ epitope in the G90D transgene product but does not recognize A337 of mouse WT opsin. Only the ROSs were labeled, indicating that the mutant opsin was trafficked appropriately and did not mislocalize as has been reported for other mutant rhodopsins in transgenic mice (Sung et al., 1994) and in postmortem eyes of humans with retinitis pigmentosa (Milam et al., 1998). The ROS labeling was intense and uniform in sections across the entire retina, confirming that the $5 \mathrm{~kb}$ upstream promoter region of the rhodopsin gene was sufficient for widespread retinal expression of G90D.
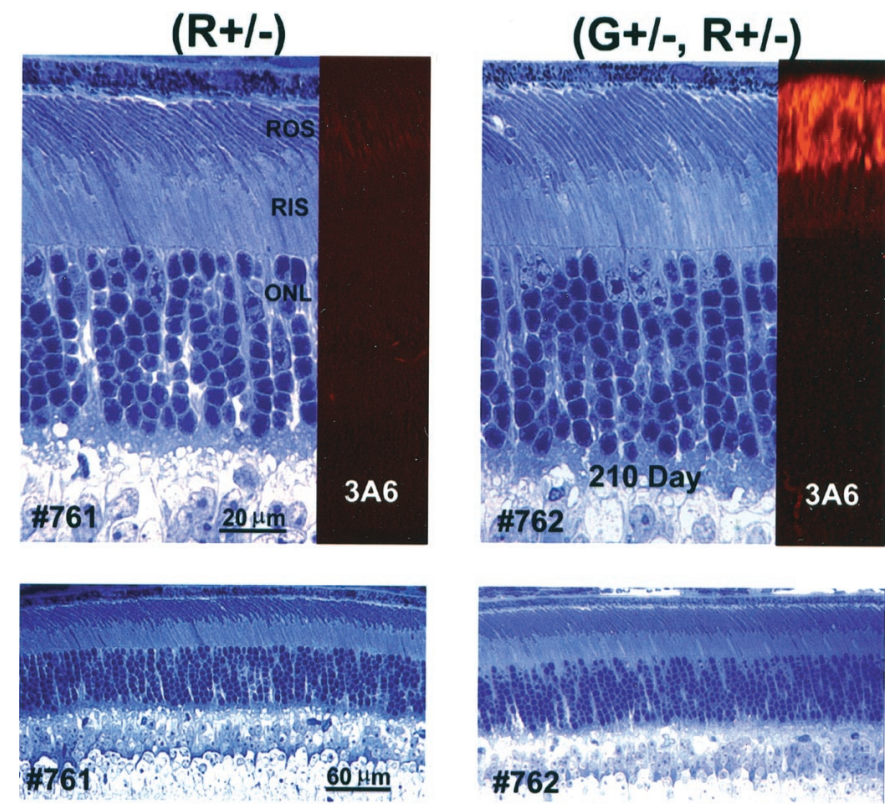

Figure 1. Histology and immunohistochemistry of 30-week-old littermate $(\mathrm{R}+/-)$ and $(\mathrm{G}+/-, \mathrm{R}+/-)$ mice. Micrographs show regions located approximately one-third the retinal distance from the optic nerve to the ora serrata at two different magnifications (top and bottom). ONL thickness was comparable in both retinas ( $\sim 9$ nuclei). At higher magnification (top), the rod outer segment lengths were similar in the two retinas, as were the inner segment lengths. Cone photoreceptor multilobed nuclei are visible just below the outer limiting membrane. Inset, The 3A6 antibody, which is specific for G90D and does not recognize WT opsin, shows proper localization of the mutant rhodopsin in the ROS

\begin{tabular}{|c|c|c|c|}
\hline Genotype & & $\begin{array}{l}\text { ROS length } \\
(\mu \mathrm{m})\end{array}$ & $\begin{array}{l}\text { ONL width } \\
\text { (cell count) }\end{array}$ \\
\hline$(\mathrm{R}+/+)$ & 30 weeks $\left(n=6^{*}\right)$ & $24.2 \pm 0.8$ & $8.77 \pm 0.34$ \\
\hline$(\mathrm{R}+/-)$ & $15-30$ weeks $(n=11)$ & $23.6 \pm 1.9$ & $8.11 \pm 0.71$ \\
\hline$(\mathrm{G}+/-, \mathrm{R}+/-)$ & 30 weeks $(n=5)$ & $23.3 \pm 1.9$ & $8.71 \pm 0.35$ \\
\hline$(\mathrm{G}+/-, \mathrm{R}+/-)$ & 51 weeks $(n=5)$ & $20.2 \pm 2.7$ & $8.01 \pm 0.97$ \\
\hline
\end{tabular}

Tabulated values give mean $\pm \mathrm{SD}$.

* Indicates $n$ is one eye each of $n$ animals, except $(\mathrm{R}+/+)$ is six eyes of three animals.

Morphometric analysis indicated that the addition of mutant G90D rhodopsin to the $(\mathrm{R}+/-)$ background did not cause degeneration (Table 1$)$. For $(\mathrm{G}+/-, \mathrm{R}+/-)$, neither ONL thickness $(p=0.10)$ nor ROS length $(p=0.52)$ was different from $(\mathrm{R}+/-)$. Similarly, comparison with $\mathrm{WT}(\mathrm{R}+/+)$ control retinas showed no difference in ONL width $(p=0.78)$ or ROS length $(p=0.31)$ for 30 week age-matched animals. Even at an age of 51 weeks, photoreceptor cell number of $(\mathrm{G}+/-, \mathrm{R}+/-)$ was not statistically different from the 30 week WT retinas, as determined by ONL width $(p=0.10)$.

\section{Rhodopsin density and absorbance spectrum}

Rhodopsin was extracted from the mouse retinas, and the amounts of WT and G90D rhodopsin were determined spectrophotometrically (Table 2). G90D formed a pigment that was bleachable with white fluorescent light (Fig. $2 A, B$ ). In retinas expressing both WT and mutant pigment, i.e., $(\mathrm{G}+/-, \mathrm{R}+/-)$, the two forms of rhodopsin were distinguished using hydroxylamine (Fig. 2, $E-G$ ). WT rhodopsin is resistant to hydroxylamine 
Table 2. Rhodopsin measurements

Rhodopsin pigment (nmol/retina)

\begin{tabular}{llllll} 
& & \multicolumn{2}{l}{ Rhodopsin pigment $($ nmol/retina) } & \\
\cline { 3 - 5 } Genotype & & Total & WT & G90D & $\lambda_{\max }(\mathrm{nm})$ \\
\hline$(\mathrm{R}+/-)$ & 18 weeks $(n=5)$ & $0.34 \pm 0.04$ & $0.34 \pm 0.04$ & - & $501.8 \pm 0.4$ \\
$(\mathrm{G}+/-, \mathrm{R}+/-)$ & 18 weeks $(n=5)$ & $0.42 \pm 0.06$ & $0.26 \pm 0.05$ & $0.16 \pm 0.02$ & \\
$(\mathrm{G}+/+, \mathrm{R}+/-)$ & 24 weeks $(n=6)$ & $0.33 \pm 0.04$ & $0.14 \pm 0.02$ & $0.20 \pm 0.02$ & \\
$(\mathrm{G}+/+, \mathrm{R}-/-)$ & 27 weeks $(n=5)$ & $0.21 \pm 0.01$ & - & $0.21 \pm 0.01$ & $492.0 \pm 0.9$ \\
\hline
\end{tabular}

Tabulated values give mean \pm SD.

treatment in darkness, but the G90D pigment becomes chemically bleached by hydroxylamine even in darkness, yielding G90D opsin and a stable retinal oxime with $\lambda_{\max }$ of $367 \mathrm{~nm}$ (Zvyaga et al., 1996). Although $(\mathrm{G}+/-, \mathrm{R}+/-)$ retinas had a greater total amount of rhodopsin than $(\mathrm{R}+/-)$ retinas $(p=0.04)$, there was a net decrease in the amount of WT rhodopsin $(p=0.02)$. Apparently, addition of the G90D allele caused downregulation of WT rhodopsin expression.

Spectrophotometric analysis gave a mean $\lambda_{\max }$ of $501.8 \mathrm{~nm}$ for WT rhodopsin and $492 \mathrm{~nm}$ for G90D (Fig. 2, Table 2). Spectra were determined by three independent assays that all gave the same result of an 8-10 nm blue-shift for the G90D pigment: (1) G90D pigment was measured directly by extracting it from $(\mathrm{G}+/+, \mathrm{R}-/-)$ animals that are expressing two G90D alleles and lack WT rhodopsin; (2) the spectral absorbance of WT rhodopsin from $(\mathrm{R}+/-)$ retinas was subtracted from measurements of $(\mathrm{G}+/-, \mathrm{R}+/-)$ retina; and $(3)(\mathrm{G}+/-, \mathrm{R}+/-)$ difference spectra were determined from absorbance measurements taken before and after treatment of the rhodopsin with hydroxylamine. G90D mouse pigment was blue-shifted similar to that of the bovine G90D spectrum previously noted by Kaushal and Khorana (1994) and by Zvyaga et al. (1996).

\section{Functional analysis}

The functional consequence of G90D opsin expression in rods was assessed by recording the ERG. In contrast to single cell recordings of rods, which were selective for responsive cells, the ERG averaged the activity of all rods in the retina. In addition, the ERG provided a gauge of the neural activity downstream from the rods. The ERG waveforms and intensity-response relations for four different genotypes are shown in Figures 3 and 4. The three genotypes with $(\mathrm{R}+/-)$ are considered here, and the remaining genotype on the $(\mathrm{R}-/-)$ background will be described below. The sensitivity of $(\mathrm{R}+/-)$ mice was $\sim 0.3 \log$ unit lower than for $(\mathrm{R}+/+)$ mice, as was also reported for the rhodopsin knock-out mice developed by Lem et al. (1999). The $(\mathrm{R}+/-)$ will provide the baseline for functional comparisons. Compared with $(\mathrm{R}+/-)$, the addition of one transgene allele $(\mathrm{G}+/-, \mathrm{R}+/-)$ resulted in a $0.37 \log$ unit sensitivity loss for the a-wave $(p<$ 0.01 ), which reflects photoreceptor activity directly (Penn and Hagins, 1969). The scotopic b-wave, which arises through activity of bipolar cells postsynaptic to the photoreceptors (Faber, 1969; Robson and Frishman, 1995; Kofuji et al., 2000), showed a sensitivity loss of $1.1 \log$ units $(p<0.01)$ (Table 3$)$. Both results
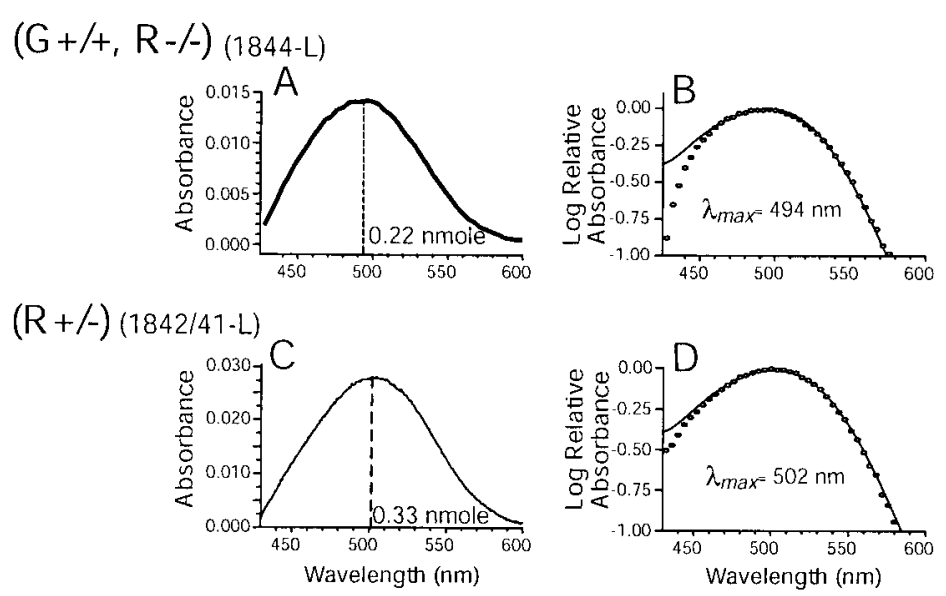

$(\mathrm{G}+/-, \mathrm{R}+/-)(1729-\mathrm{L})$
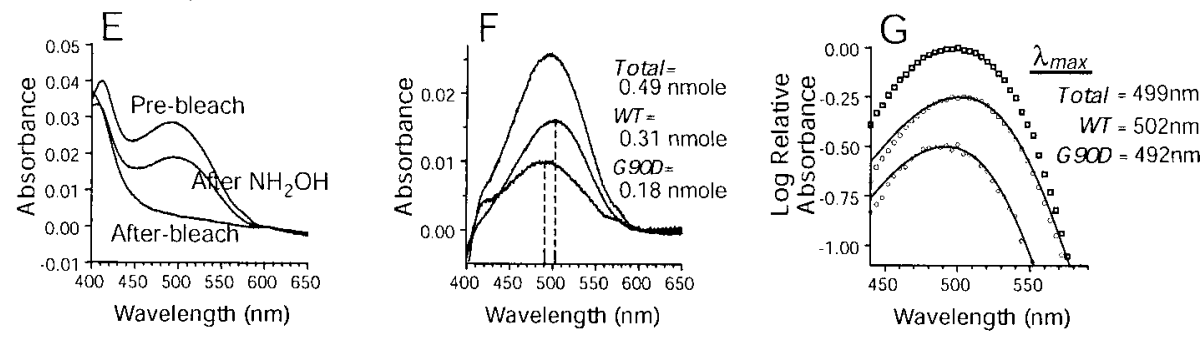

Figure 2. Visual pigment absorbance spectra. $A, B$, Difference spectra from a $(\mathrm{G}+/+, \mathrm{R}-/-)$ mouse expressing only G90D pigment. $C, D$, Difference spectra from an $(\mathrm{R}+/-)$ mouse expressing only WT pigment. Molar amounts (nanomoles per retina) were calculated using the extinction coefficients $42,700 \mathrm{M}^{-1} \mathrm{~cm}^{-1}$ for WT and $37,000 \mathrm{M}^{-1} \mathrm{~cm}^{-1}$ for G90D (Zvyaga et al., 1996). $B, D$, Spectral maxima were derived by least-squares fitting of the $\log$ relative absorbance data with a polynomial implementation (Dawis, 1981) of the Dartnall (1953) nomogram. $E-G$, Hydroxylamine separation of G90D from WT pigment in a $(\mathrm{G}+/-, \mathrm{R}+/-)$ mouse. $E$, The spectrum of the rhodopsin extract was measured (Pre-bleach) and then remeasured after sequential exposure to hydroxylamine (After $\mathrm{NH}_{2} \mathrm{OH}$ ) and light (After-bleach), respectively. The raw spectra were zeroed at $700 \mathrm{~nm} . F$, The calculated difference spectra. Subtraction of After $\mathrm{NH}_{2} \mathrm{OH}$ from the Pre-bleach spectra gives the G90D spectrum; subtraction of After-bleach from After $\mathrm{NH}_{2} \mathrm{OH}$ spectra gives the WT spectrum. Molar amounts of each rhodopsin were calculated using the appropriate extinction coefficients for each pigment (as above). $G$, Spectral maxima of G90D and WT rhodopsin derived by leastsquares fitting of the difference spectra to the Dartnall nomogram. Fitting to the mixture (Total ) pigment data indicated a $\lambda_{\max }$ of $\sim 499 \mathrm{~nm}$, although this fit is not shown, because the nomogram must be adjusted for the mixed G90D plus WT pigments. 


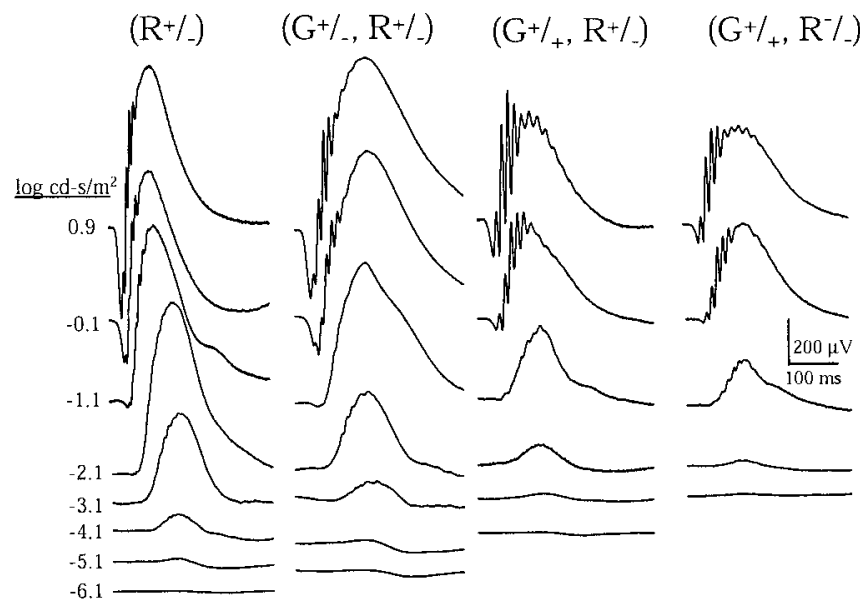

Figure 3. Dark-adapted ERG responses recorded in vivo. Flash densities are given on the left. Responses are from single animals representative of each genotype. Traces show averages of 10 trials, except for the responses to the two brightest flashes, which were single trials.

were highly significant and could not be accounted for by a change in photon capture, because the total rhodopsin content of the $(\mathrm{G}+/-, \mathrm{R}+/-)$ retina was greater than that of $(\mathrm{R}+/-)(p=0.04)$ (Table 2). $(\mathrm{G}+/-, \mathrm{R}+/-)$ retinas had $0.12 \log$ unit less WT rhodopsin than $(\mathrm{R}+/-)$ retinas, but even if it were argued that G90D rhodopsin was inactive and that only WT rhodopsin contributed to the photoresponse, the $0.12 \log$ unit decrease of photon catch by WT rhodopsin could not account for the sensitivity loss. Nor was the desensitization caused by loss of photoreceptor cells, because even at 30 weeks of age, the $(\mathrm{G}+/-$, $\mathrm{R}+/-$ ) retina showed good preservation of photoreceptors compared with $(\mathrm{R}+/-)$ littermates (Fig. 1). Comparable loss of ERG threshold sensitivity was also observed in recordings of young, 3to 4-week-old ( $\mathrm{G}+/-, \mathrm{R}+/-)$ animals (data not shown), consistent with a congenital phenotype. The a-wave recordings demonstrate that the locus of the retinal sensitivity loss lies within the rods.

Adding the second G90D allele, i.e., $(\mathrm{G}+/+, \mathrm{R}+/-)$ animals, caused a further substantial sensitivity loss, greatly disproportionate to the minimal change in rod count or ROS length (Table 4; see Discussion for $\mathrm{P} 23 \mathrm{H}$ rhodopsin mutant animals). ONL width of $(\mathrm{G}+/+, \mathrm{R}+/-)$ remained essentially identical to $(\mathrm{R}+/-)(p=$ $0.96)$, and ROS length was only $12 \%$ shorter $(p=0.03)$. A-wave threshold was desensitized by $1.1 \log$ units from $(\mathrm{R}+/-)$, and b-wave threshold shifted $2 \log$ units. Total rhodopsin density in $(\mathrm{G}+/+, \mathrm{R}+/-)$ was essentially the same as in $(\mathrm{R}+/-)$, with $60 \%$ in the mutant G90D form.

Photoreceptor function was examined further by placing paired electrodes across the photoreceptor layer in isolated retinas to record photoreceptor responses with minimal contamination from responses of other cell types located in other retinal layers. $(\mathrm{G}+/-, \mathrm{R}+/-)$ rods showed a threshold shift of $0.66 \mathrm{log}$ units at higher flash strengths when compared with $(\mathrm{R}+/-)$ rods (Fig. $5 C)$. The $(\mathrm{G}+/-, \mathrm{R}+/-)$ rod photoresponses also had a shorter time-to-peak compared with $(\mathrm{R}+/-)$ responses (Fig. 6). Faster response kinetics and decreased sensitivity are associated with light adaptation (Dowling, 1967; Baylor et al., 1984), and these results indicate that G90D pigment caused the $(\mathrm{G}+/-$, $\mathrm{R}+/-$ ) rods to act as if they were light adapted even when they were maintained in darkness. The $(\mathrm{R}+/-)$ rod photoresponses
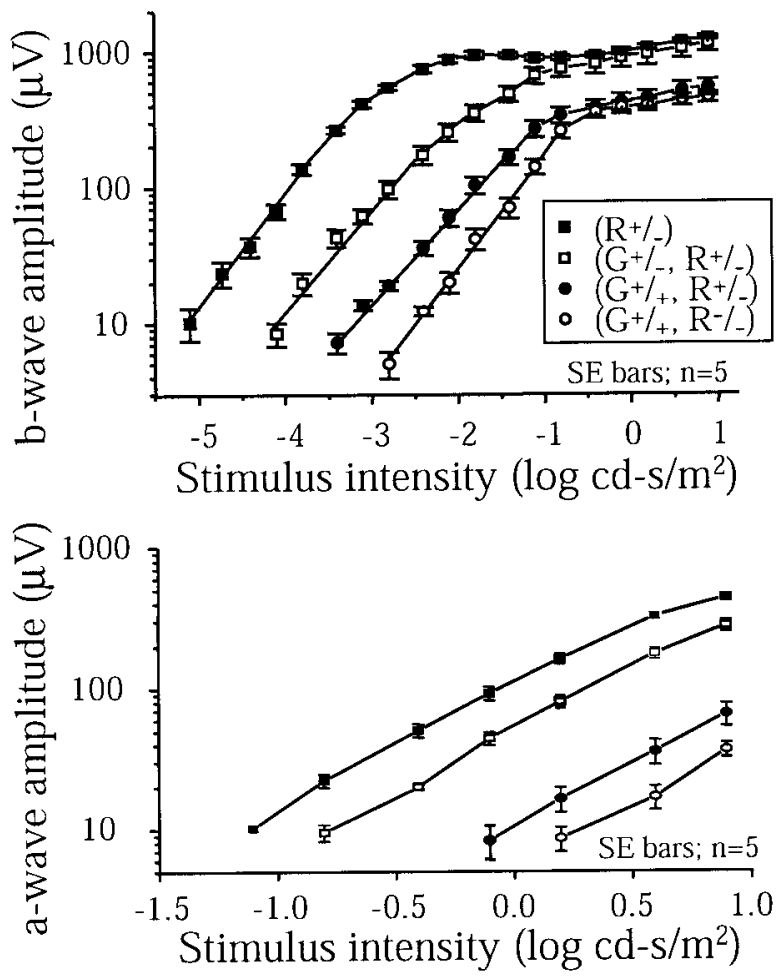

Figure 4. Dark-adapted ERG stimulus-response relations for the b-wave (top) and a-wave (bottom) recorded in vivo as in Figure 3. To avoid contamination by postphotoreceptoral ERG sources, the a-wave amplitudes were measured at a fixed time after flash onset equivalent to 14 msec after appearance of the a-wave for dim flashes and were not measured at the a-wave trough, which changes in time with flash intensity. Five mice of each genotype were recorded at the following ages: $(\mathrm{R}+/-)$, 17 weeks; $(\mathrm{G}+/-, \mathrm{R}+/-), 16$ weeks; $(\mathrm{G}+/+, \mathrm{R}+/-), 24$ weeks; $(\mathrm{G}+/+$, $\mathrm{R}-/-), 27$ weeks.

had a slightly shorter time-to-peak compared with $(\mathrm{R}+/+)$ responses (Fig. 5) as has been reported by Lem et al. (1999); this may result from increased mobility of rhodopsin in the disc membrane consequent to its decreased density in $(\mathrm{R}+/-)$.

The dark activity of G90D rhodopsin in producing this threshold elevation of $(\mathrm{G}+/-, \mathrm{R}+/-)$ retinas was estimated by observing the effect of an adapting background light in elevating the threshold of WT $(\mathrm{R}+/+)$ retinas $($ Fig. $5 D-F)$. The $0.66 \log$ unit decrease in photoresponse sensitivity of $(\mathrm{G}+/-, \mathrm{R}+/-)$ compared with $(\mathrm{R}+/-)$ could be replicated in WT by exposing the retina to environmental light equivalent to 328 quanta $\operatorname{rod}^{-1}$ $\sec ^{-1}$ (Fig. $5 F$ ), which shifted the WT sensitivity rightward by $\sim 0.7 \log$ unit using a criterion of one-half amplitude of the dark-adapted responses. Using standard assumptions that $25 \%$ of photons incident on the rod are absorbed and isomerize rhodopsin (designated $\mathrm{Rh}^{*}$ ) (Cone, 1963), this indicated that the G90D rods behaved as if they were being stimulated internally by an "equivalent light" of $82 \mathrm{Rh}^{*} \operatorname{rod}^{-1} \mathrm{sec}^{-1}$.

A second estimate of G90D endogenous noise was developed from the ERG a-wave recordings of the intact eye (Fig. 3). Threshold of the $(\mathrm{G}+/-, \mathrm{R}+/-)$ a-wave response was shifted $0.37 \log$ unit compared with $(\mathrm{R}+/-)$ (Table 3$)$. The calibration derived above was used, i.e., that exposure to environmental light of 328 quanta $\mathrm{rod}^{-1} \mathrm{sec}^{-1}$ (Fig. 5) desensitized WT photovoltages by $0.7 \log$ unit. Assuming that the Weber-Fechner fraction of increment threshold is linear in this range and that $25 \%$ of incident photons isomerize rhodopsin, the equivalent light inter- 
(A) $\quad(\mathrm{R}+/) \quad n=4$

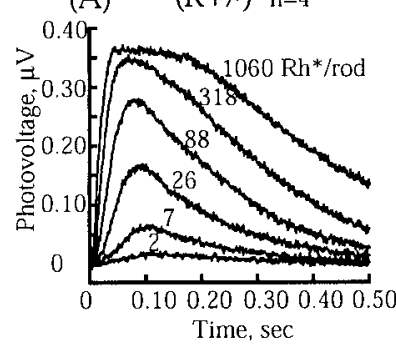

$(\mathrm{R}+/+) \mathrm{n}=5$
(D)

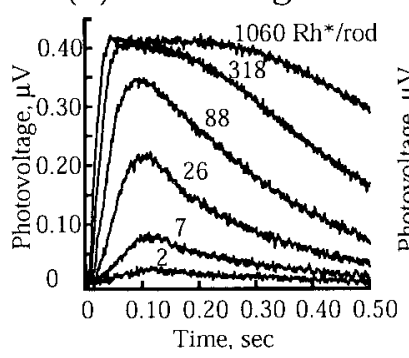

(B) $(\mathrm{G}+/, \mathrm{R}+/) \quad \mathrm{n}=7$

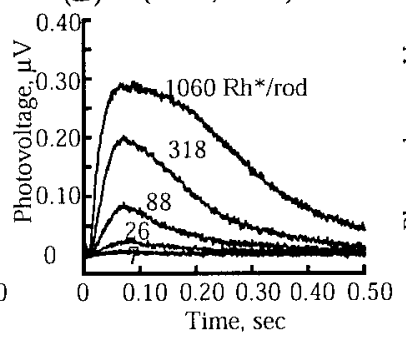

Time, sec

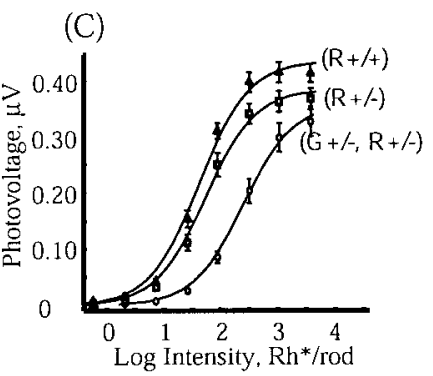

$(\mathrm{R}+/+) \mathrm{n}=2$ (E) With Background

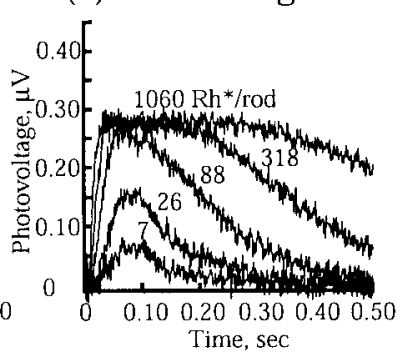

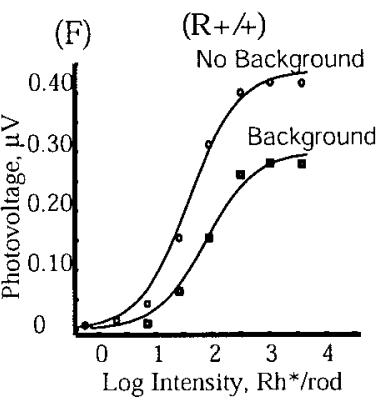

Figure 5. Rod a-wave photovoltages recorded from the isolated retinas of 14- to 16-week-old animals. Flash strengths increased by one-half $\log$ unit steps up to a maximum of $1060 \mathrm{Rh}^{*}$ $\operatorname{rod}^{-1}$ flash $^{-1}$. Flashes were given at time 0 . $A-C$ show the sensitivity shift from the G90D transgene on heterozygous rhodopsin knockout background. $A, B$, Rod photovoltage responses of $(\mathrm{R}+/-)$ and $(\mathrm{G}+/-, \mathrm{R}+/-)$ retinas. $C$, The intensity-response relationships were fitted with Michaelis-Menten functions of $V_{\max } I /(I+\sigma)$. Values of $V_{\max }($ in $\mathrm{mV}$ ) were $0.438,0.387$, and 0.361 for $(\mathrm{R}+/+),(\mathrm{R}+/-)$, and $(\mathrm{G}+/-, \mathrm{R}+/-)$, respectively, and sigma values (in $\mathrm{Rh}^{*} \operatorname{rod}^{-1}$ flash $^{-1}$ ) were 43,55 , and 251 , respectively. ( $\mathrm{G}+/-, \mathrm{R}+/-$ ) curve shows a rightward sensitivity shift of $0.66 \log$ unit from $(\mathrm{R}+/-) . D-F$ show the sensitivity shift of rod photovoltage of WT retina after the application of a light-adapting background. Dark-adapted $(D)$ and with a steady background $(E)$ of 328 quanta $\mathrm{rod}^{-1} \mathrm{sec}^{-1}$ (equivalent to $82 \mathrm{Rh}^{*} \operatorname{rod}^{-1} \mathrm{sec}^{-1}$ ) that decreases the response sensitivity and shifts the intensity-response curve right by $0.70 \log$ unit to reach the criterion response of one-half darkadapted response amplitude $(F)$. nal to each rod photoreceptor was $38 \mathrm{Rh}^{*} \operatorname{rod}^{-1} \mathrm{sec}^{-1}$ by this measure.

A third estimate of G90D endogenous activity can be obtained from the sensitivity shift observed for the b-wave that was recorded from the intact eye (Fig. 3). B-wave threshold for $(\mathrm{G}+/-$, $\mathrm{R}+/-$ ) was shifted by $1.09 \log$ units compared with $(\mathrm{R}+/-)$ animals (Table 3). Using the increment sensitivity function that we had previously determined for WT mice (Toda et al., 1999), this shift represents an equivalent background of -1.92 log photopic $\mathrm{cd} / \mathrm{m}^{2}$, or $32 \mathrm{Rh}^{*} \operatorname{rod}^{-1} \mathrm{sec}^{-1}$. From these several different and independent estimates, rods in the $(\mathrm{G}+/-, \mathrm{R}+/-)$ acted as though they were exposed to an equivalent internal light in the range of 32-82 $\mathrm{Rh}^{*} \operatorname{rod}^{-1} \mathrm{sec}^{-1}$. This is roughly in the range of or slightly higher than the "equivalent background" of $10 \mathrm{Rh}^{*}$ $\operatorname{rod}^{-1} \mathrm{sec}^{-1}$ that was estimated for the G90D human family with autosomal dominant congenital nightblindness (Sieving et al., 1995).

Adding the second G90D allele, $(\mathrm{G}+/+, \mathrm{R}+/-)$ animals, increased the relative expression of mutant rhodopsin and gave total rhodopsin quantity comparable with $(\mathrm{R}+/-)$ retina (Table $2)$. The b-wave threshold shift was $2.05 \log$ units for $(\mathrm{G}+/+$, $\mathrm{R}+/-)$, compared with $(\mathrm{R}+/-)$ animals (Table 3 ). Increment threshold studies with WT showed that a comparable shift resulted from a steady background of $-0.90 \mathrm{log} \mathrm{cd} / \mathrm{m}^{2}$ (Toda et al., 1999) or $\sim 390 \mathrm{Rh}^{*} \operatorname{rod}^{-1} \mathrm{sec}^{-1}$.

\section{G90D on (R-/-) genetic background}

G90D as a structural substitute for WT rhodopsin

Line 202 animals were bred further to put both single and double alleles of the G90D transgene on the homozygous knock-out $(\mathrm{R}-/-)$ background (Figs. 7,8$)$. Both the $(\mathrm{R}-/-)$ and $(\mathrm{G}+/-$, $\mathrm{R}-/-$ ) retinas initially develop essentially normal numbers of photoreceptor nuclei, as shown by ONL column counts at 4 weeks (Table 4). However, the $(\mathrm{R}-/-)$ retina does not produce rhodopsin and does not form ROS; instead, it has a zone of amorphous material between the ONL and RPE. $(\mathrm{R}-/-)$ has progressive loss of rod nuclei, and cone nuclei are also subsequently lost. By 14 weeks, only two or fewer rows of photoreceptor nuclei remain (Fig. 7). In contrast, rods in the $(\mathrm{G}+/-, \mathrm{R}-/-)$ retina do express rhodopsin (Fig. 7), and they successfully elaborate outer segments. Although this demonstrates that G90D opsin can serve as a structural substitute for WT rhodopsin in the elaboration of ROS, the $(\mathrm{G}+/-, \mathrm{R}-/-)$ retina still degenerates slowly with age. At 14 weeks, ROSs are still present, but the ONL thickness is only $\sim 60 \%$ of normal.

We suspected that the slow degeneration in the $(\mathrm{G}+/-, \mathrm{R}-/-)$ retina might result from a gene dosage effect, because a single transgene allele expresses opsin at approximately one-half the level of a single WT allele $[(\mathrm{G}+/-, \mathrm{R}+/-)$ versus $(\mathrm{R}+/-)$ retina; Table 2], and some loss of photoreceptor cells was observed in $(\mathrm{R}+/-)$ retinas at a later age (Humphries et al., 1997; Lem et al., 1999). This possibility was explored by evaluating mice with two G90D alleles on the knock-out background $(\mathrm{G}+/+, \mathrm{R}-/-)$. Mice were identified by quantitative mRNA analysis, which showed three relatively discrete levels of G90D mRNA corresponding to the presence of zero, one, or two G90D alleles. The G90D double allele status was confirmed then by mating with $\mathrm{WT}(\mathrm{R}+/+)$ mice in which all progeny carried the G90D transgene in tail DNA assays of $>20$ pups and all progeny of mating with $(\mathrm{R}-/-)$ lacked the WT alleles. The number of G90D alleles in progeny was determined then by quantitative RT-PCR, which indicated the result unambiguously. Examples of $(\mathrm{G}+/+, \mathrm{R}-/-)$ retinas are shown in Figure 8. Both retinas show substantial photoreceptor rescue at 36 and 55 weeks of age, with ONL thickness of 6-8 cells and ROS length of 20-22 $\mu \mathrm{m}$. Electron microscopy of the 36week-old retina showed well formed ROS with uniform disc spacing and good registration of the disc rims at the ROS plasma membrane (Fig. 8). Even heterozygous rhodopsin knock-out mice, without the transgene, show some ONL thinning by 1 year of age (Fig. 8), and three $(\mathrm{R}+/-)$ retinas at 14 months of age averaged approximately five cell ONL widths. Consequently the $(\mathrm{G}+/+, \mathrm{R}-/-)$ retinas show good photoreceptor preservation at this age.

The rescue effect of two G90D alleles was evaluated further by comparing structure and function of littermates, with five $(\mathrm{G}+/+$, 

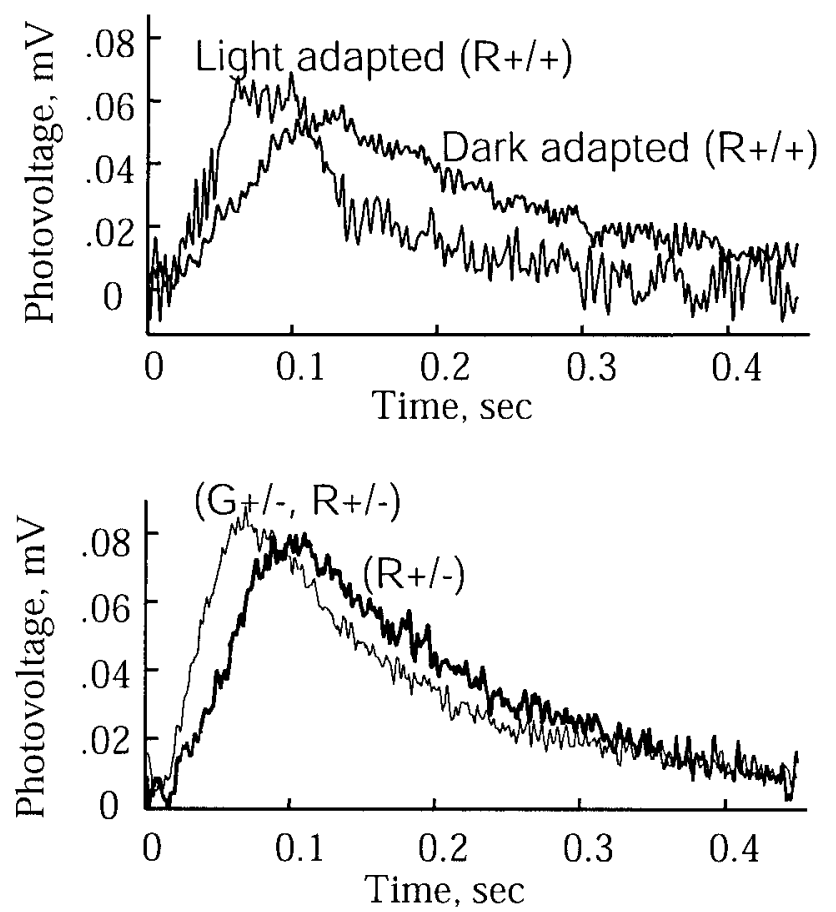

Figure 6. Kinetics of averaged, normalized rod a-wave photovoltages elicited by dim flashes and recorded from excised retinas. Top, $(\mathrm{R}+/+)$ animals show faster time to peak of the light-adapted rod response compared with the dark-adapted response. Bottom, The $(\mathrm{G}+/-, \mathrm{R}+/-)$ response has faster kinetics than the $(\mathrm{R}+/-)$ response in which both were recorded in complete darkness.

$\mathrm{R}+/-)$ mice and five $(\mathrm{G}+/+, \mathrm{R}-/-)$ mice obtained from parental mating of $(\mathrm{G}+/+, \mathrm{R}-/-)$ to $(\mathrm{G}+/-, \mathrm{R}+/-)$, with genotypes confirmed by analysis of tail DNA as above. At 24-27 weeks, retinas of $(\mathrm{G}+/+, \mathrm{R}+/-)$ and $(\mathrm{G}+/+, \mathrm{R}-/-)$ genotypes had similar ROS length $(p=0.85)$, and the ONL width was nearly the same (Table 4). The ERG, however, showed that eliminating the WT allele caused a sensitivity loss (Table 3 ). Compared with $(\mathrm{G}+/+, \mathrm{R}+/-)$ mice, b-wave threshold of $(\mathrm{G}+/+, \mathrm{R}-/-)$ mice was elevated by $0.63 \log$ unit $(p<0.01)$, and the a-wave threshold was elevated by $0.41 \log$ unit $(p<0.01)$. Retinal rhodopsin measurements of these same 10 mice showed that they differed only by the presence or absence of WT rhodopsin, because the quantity of G90D rhodopsin was identical in the two genotypes at $\sim 0.2 \mathrm{nmol}$ per retina (Table 2 ). The total rhodopsin density in the $(\mathrm{G}+/+, \mathrm{R}-/-)$ retinas was $64 \%$ of $(\mathrm{G}+/+, \mathrm{R}+/-)$ retinas, accounting for $0.19 \mathrm{log}$ unit elevation of a-wave threshold by photon catch loss. The remaining $0.22 \mathrm{log}$ unit difference in a-wave threshold can be attributed to the lower efficiency of G90D function measured in vitro by Zvyaga et al. (1996), in which the G90D extinction coefficient was $13 \%$ lower and activation of transducin by G90D was $41 \%$ less than that of WT rhodopsin, with a net functional efficiency of G90D lower than WT by 0.29 log unit. Zvyaga et al. (1996) also noted that the G90D activated in vitro was 4.6 times shorter than WT rhodopsin. This factor should not play a role in vivo, however, because phosphorylation and arrestin binding quench the rhodopsin $\mathrm{R}^{*}$ active state rather than a thermal transition. The lifetime of WT meta-II active state is $\sim 1-2 \mathrm{~min}$ at $37^{\circ} \mathrm{C}$. If the G90D rhodopsin lifetime is foreshortened to $60 \mathrm{sec} / 4.6=13 \mathrm{sec}$, this is still far slower than inactivation by phosphorylation that begins within $100 \mathrm{msec}$ of $\mathrm{R}^{*}$ formation and is complete within $500 \mathrm{msec}$ (Chen et al., 1995) and by
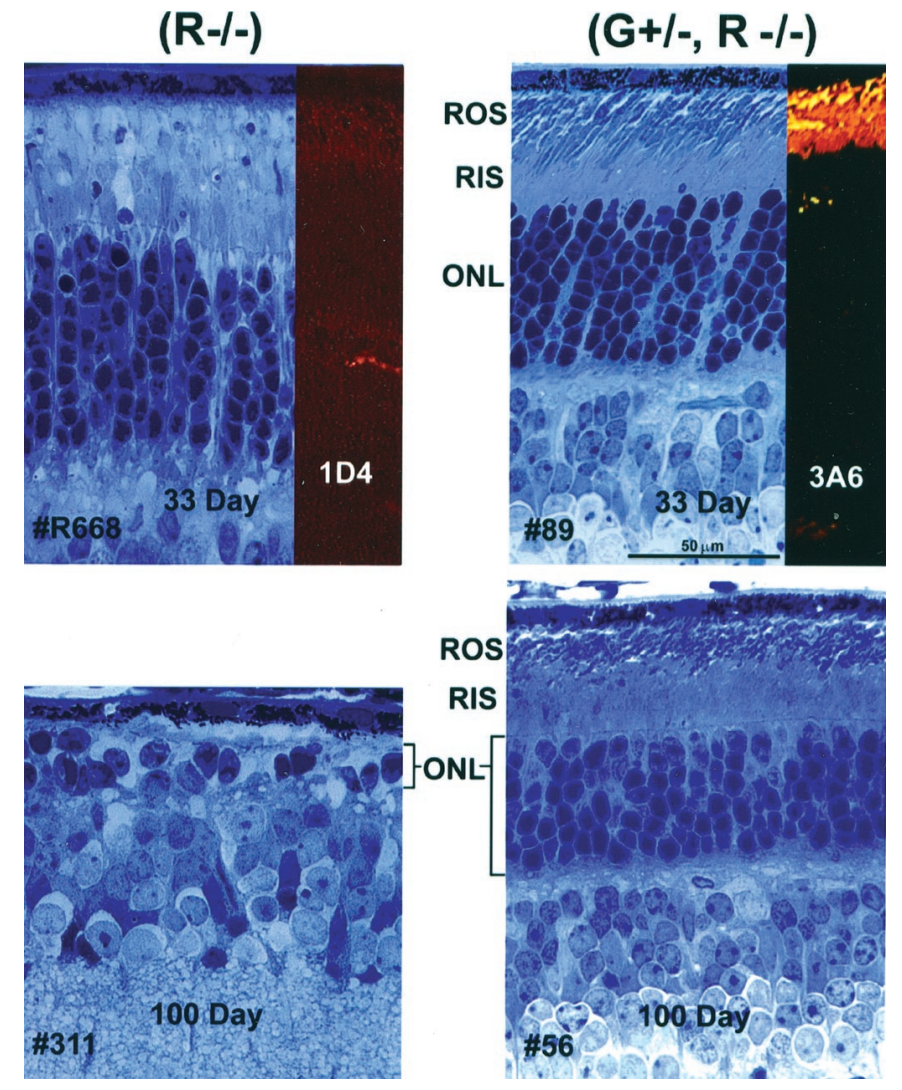

Figure 7. Rescue by G90D rhodopsin. Top, Five week (R-/-) has normal ONL but no structured ROS, and 1D4 antibody shows no opsin expression (inset, top left). Five week $(\mathrm{G}+/-, \mathrm{R}-/-)$ develops ROS with G90D opsin expression as shown by the 3A6 antibody labeling (inset, top right). Bottom, Fourteen week ( $\mathrm{R}-/-)$ ONL has degenerated to less than a single row of cells that are mostly cone multilobed nuclei. Fourteen week $(\mathrm{G}+/-, \mathrm{R}-/-)$ shows relative rod rescue with an ONL thickness of approximately six nuclei and ROS still present.

arrestin binding that commences within $150 \mathrm{msec}(\mathrm{Xu}$ et al., 1997).

\section{G90D rhodopsin supports phototransduction in rods}

$(\mathrm{R}-/-)$ mice have a negligible a-wave even under dark-adapted conditions [e.g., see the $(\mathrm{R}-/-)$ responses in Toda et al., (1999)]. This is not surprising because all ERG activity of $(\mathrm{R}-/-)$ mice is cone-mediated, even under dark-adapted conditions (Toda et al., 1999), and the murine cone-driven photopic a-wave is quite small. Consequently the presence of a dark-adapted a-wave in the recordings of $(\mathrm{G}+/+, \mathrm{R}-/-)$ mice in Figures 3 and 4 is evidence that G90D rhodopsin can mediate light-evoked rod responses in vivo. Furthermore, the b-wave threshold of $(\mathrm{G}+/+, \mathrm{R}-/-)$ is 1.4 $\log$ units lower than the threshold of cone responses of $(\mathrm{R}-/-)$ (Table 3), which further indicates that G90D rods can mediate light responses.

\section{DISCUSSION}

\section{G90D fulfillment of the ROS requirement for rhodopsin}

$(\mathrm{R}-/-)$ rods lack rhodopsin and fail to produce outer segments (Humphries et al., 1997; Lem et al., 1999). The presence of ROS in $(\mathrm{G}+/-, \mathrm{R}-/-)$ indicates that G90D provides a suitable replacement for WT rhodopsin. Nevertheless, rods from $(\mathrm{G}+/-$, $\mathrm{R}-/-$ ) animals were slowly lost with age. However, with the increased G90D expression in $(\mathrm{G}+/+, \mathrm{R}-/-)$ mice, roughly 


\begin{tabular}{|c|c|c|c|c|c|}
\hline Genotype & & $\begin{array}{l}\text { Maximal b-wave } \\
\text { amplitude }(\mu \mathrm{V})\end{array}$ & $\begin{array}{l}\text { B-wave threshold } \\
\left(\log \mathrm{cd}-\mathrm{sec} \mathrm{m}^{-2} \text { ) }\right.\end{array}$ & $\begin{array}{l}\text { Maximal a-wave } \\
\text { amplitude }(\mu \mathrm{V})\end{array}$ & $\begin{array}{l}\text { A-wave threshold } \\
\left(\log \text { cd-sec } \mathrm{m}^{-2}\right)\end{array}$ \\
\hline$(\mathrm{R}+/-)$ & 7 weeks $(n=5)$ & $1259 \pm 77$ & $-4.79 \pm 0.34$ & $498 \pm 50$ & $-0.83 \pm 0.10$ \\
\hline$(\mathrm{G}+/-, \mathrm{R}+/-)$ & 16 weeks $(n=5)$ & $1152 \pm 344$ & $-3.70 \pm 0.19$ & $320 \pm 89$ & $-0.46 \pm 0.06$ \\
\hline$(\mathrm{G}+/+, \mathrm{R}+/-)$ & 24 weeks $(n=5)$ & $547 \pm 166$ & $-2.74 \pm 0.11$ & $113 \pm 37$ & $0.27 \pm 0.16$ \\
\hline$(\mathrm{G}+/+, \mathrm{R}-/-)$ & 27 weeks $(n=5)$ & $460 \pm 97$ & $-2.11 \pm 0.10$ & $76 \pm 16$ & $0.68 \pm 0.13$ \\
\hline$(\mathrm{R}-/-)$ & 4 weeks $(n=16)$ & $343 \pm 59$ & $-0.70 \pm 0.40$ & Negligible** & - \\
\hline
\end{tabular}

Tabulated values give mean $\pm \mathrm{SD}$. Criterion response levels were $20 \mu \mathrm{V}$ for a-wave and b-wave thresholds.

$* *(\mathrm{R}-/-)$ mice have only cone-mediated activity and consequently a negligible a-wave.

one-fourth to one-half of normal WT rhodopsin levels, rod survival was markedly prolonged, with only minimal rod loss even at 1 year of age. Interestingly, the presence of the G90D transgene appeared to downregulate the expression of WT rhodopsin when added to $(\mathrm{R}+/-)$ background. Because a twofold increase in transgene copy number, from one to two alleles, yielded less than a twofold increase in G90D rhodopsin, there may have been some downregulation of G90D expression as well.

\section{"Dark-light" in G90D vision}

The human G90D phenotype of congenital nightblindness in the absence of clinically apparent retinal degeneration led us to hypothesize that rod function was impaired separately from any rod loss (Sieving et al., 1995). This is now supported by findings in these G90D mice. $(\mathrm{G}+/-, \mathrm{R}+/-)$ mice as young as 3-4 weeks of age showed the rod functional deficit, consistent with the human G90D congenital phenotype. The desensitization increased with the number of G90D alleles expressed. G90D formed a bleachable pigment that supported normal photoactivation of transduction leading to rod responses in vivo. Therefore, the desensitization cannot be explained by a decreased quantal catch or by an inability to generate a photoresponse. G90D pigment in mice also decreased the maximal a-wave and b-wave amplitudes and caused an acceleration of the rod response kinetics. As also occurs for retinal desensitization from a background light (Green and Powers, 1982), desensitization of the b-wave was greater than that of the a-wave in G90D animals.

These effects were mimicked in WT rods by exposing them to continuous environmental light. Background light giving rise to $82 \mathrm{Rh}^{*} \operatorname{rod}^{-1} \mathrm{sec}^{-1}$ caused a sensitivity change in WT rod photovoltages comparable with that from adding a single G90D allele to the $(\mathrm{R}+/-)$ genotype. Endogenous G90D light was also observed on ERG recordings that indicated an equivalent of 38 $\mathrm{Rh}^{*} \operatorname{rod}^{-1} \mathrm{sec}^{-1}$ for the a-wave sensitivity loss and $32 \mathrm{Rh}^{*}$ rod $^{-1}$ $\mathrm{sec}^{-1}$ for the b-wave shift for $(\mathrm{G}+/-, \mathrm{R}+/-)$ vs $(\mathrm{R}+/-)$. This is 3-4 log units greater than the normal WT rate of photon-like discrete noise events of $\sim 0.01 \operatorname{rod}^{-1} \mathrm{sec}^{-1}$ measured from

\section{Table 4. Morphometric analysis}

\begin{tabular}{lrlr} 
Genotype & & $\begin{array}{l}\text { ROS } \\
\text { length }(\mu \mathrm{m})\end{array}$ & $\begin{array}{l}\text { ONL width } \\
(\text { cell count })\end{array}$ \\
\hline$(\mathrm{G}+/+, \mathrm{R}+/-)$ & 24 weeks $(n=5)$ & $20.8 \pm 1.5$ & $8.13 \pm 0.34$ \\
$(\mathrm{G}+/+, \mathrm{R}-/-)$ & 27 weeks $(n=5)$ & $21.0 \pm 1.9$ & $7.62 \pm 0.40$ \\
$(\mathrm{G}+/-, \mathrm{R}-/-)$ & 4 weeks $(n=6)$ & $19.8 \pm 2.5$ & $8.88 \pm 0.75$ \\
$(\mathrm{R}-/-)$ & 4 weeks $(n=6)$ & $\begin{array}{c}\text { Amorphous } \\
\text { material* }\end{array}$ & $9.33 \pm 0.38$ \\
& & m
\end{tabular}

Tabulated values give mean $\pm \mathrm{SD}$.

* $(\mathrm{R}-/-)$ has a zone of amorphous material with no formed ROS.
Macaca fascicularis rods in darkness (Baylor et al., 1984). The phosphodiesterase activity produced by this level of equivalent endogenous light would be sufficient to explain much of the flash desensitization and acceleration of the flash response kinetics (Nikonov et al., 2000). The in vivo measurements from G90D mice are consistent with in vitro biochemical studies demonstrating that G90D rhodopsin activates transducin in darkness (Rao et al., 1994). We conclude that G90D rhodopsin gives rise to an increased intrinsic noise equivalent to an endogenous dark-light signal that leaves the rod in a desensitized, partially light-adapted state. This distinguishes the G90D phenotype from other forms of congenital stationary nightblindness caused by synaptic or trans-synaptic deficits (Bech-Hansen et al., 2000).
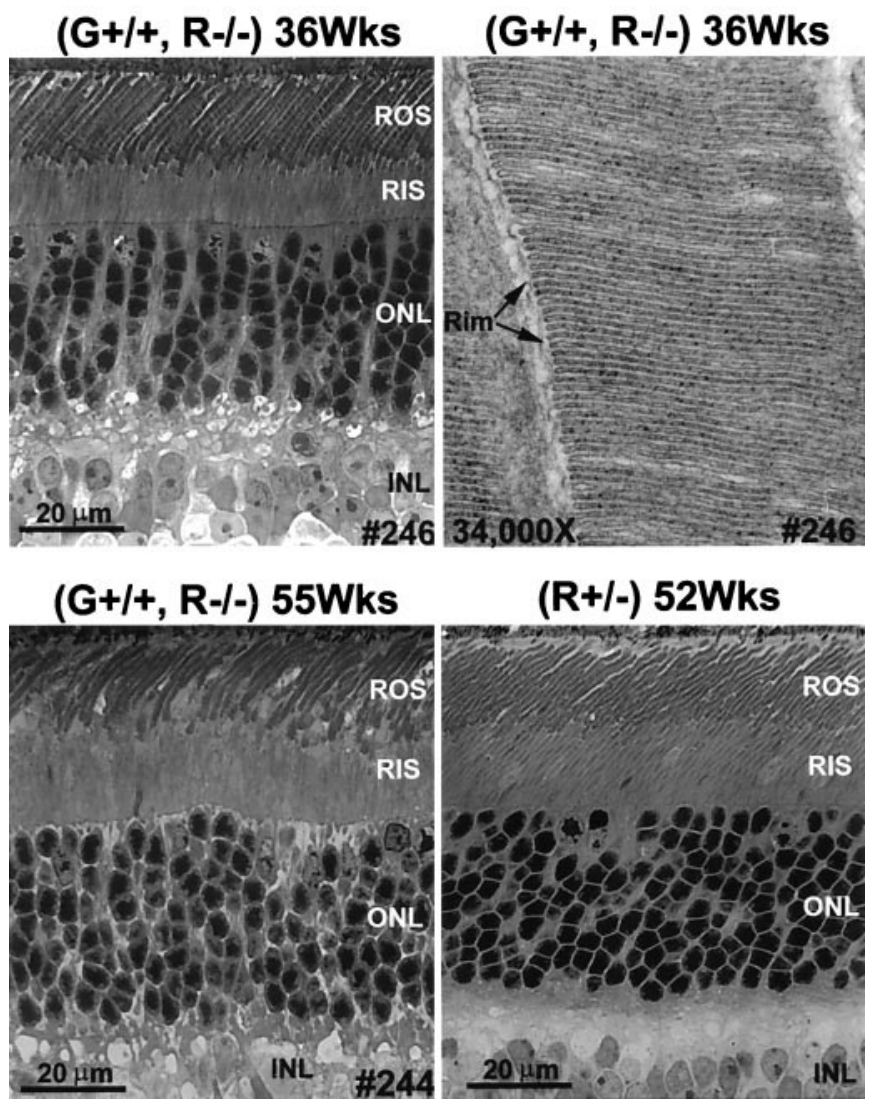

Figure 8. Histology from two $(\mathrm{G}+/+, \mathrm{R}-/-)$ retina at ages of 36 and 55 weeks. Both show minimal ONL thinning and ROS of nearly normal length. Electron microscopy of the 36 week retina shows well formed ROS with uniformly spaced discs and good registration of the disc rims at the ROS plasma membrane. The $(\mathrm{R}+/-)$ also shows $\mathrm{ONL}$ thinning in a representative 52-week-old mouse. 
G90D rhodopsin has properties that mimic cone pigment: G90D is spectrally shifted from rhodopsin, G90D is chemically degraded by hydroxylamine, photoactivated G90D decays more rapidly than WT rhodopsin, and G90D activates the phototransduction cascade in darkness. Dark activity by cone pigments, particularly the long-wavelength pigment, arises from thermal instability (Schnapf et al., 1990; Rieke and Baylor, 2000). At present, it is unclear whether the G90D mutation decreases the thermal stability of rhodopsin or whether it partially activates rhodopsin (Zvyaga et al., 1996). Thermal instability would increase the rate of single photon response-like events, whereas partial rhodopsin activation would result in a higher basal rate of continuous phosphodiesterase activity. G90D subjects specifically deny perceiving discrete photopsias (P. Sieving, unpublished observation in querying G90D affected subjects). This may not be surprising, however, because the thermal isomerization rates of 32-82 $\mathrm{Rh}^{*}$ rod $^{-1} \mathrm{sec}^{-1}$ estimated here for $(\mathrm{G}+/-, \mathrm{R}+/-)$ mice or the $10 \mathrm{Rh}^{*} \operatorname{rod}^{-1} \mathrm{sec}^{-1}$ that we previously estimated for G90D affected subjects (Sieving et al., 1995) would produce many excitation events during the rod normal integration period, estimated as nominally $275 \mathrm{msec}$ in monkey Macaca fascicularis (Baylor et al., 1984) and in mouse (Raport et al., 1994). Discrete noise events would also not be distinguishable in physiological recordings. Fourier transform infrared spectroscopy suggested that G90D rhodopsin adopts a conformation that is more similar to photoisomerized rhodopsin than to dark-adapted WT rhodopsin, but this does not distinguish between a lowered activation energy for thermal isomerization and/or causing chronic partial activity (Zvyaga et al., 1996).

Although mutant K296E rhodopsin shows consecutive activity in vitro, with or without 11-cis-retinal (Robinson et al., 1992), the story is more complex in vivo, because K296E rhodopsin is phosphorylated and stably bound to arrestin and consequently is completely shut off, with the result that K296E transgenic mice fail to demonstrate rod light-adaptation by ERG analysis ( $\mathrm{Li}$ et al., 1995). By comparison, responses of both $(\mathrm{G}+/+, \mathrm{R}-/-)$ (Fig. $3)$ and $(\mathrm{G}+/-, \mathrm{R}+/-)$ (Fig. 5) mice roughly resembled the $(\mathrm{R}+/-)$ responses, and neither showed prolonged recovery as is found in those rhodopsin mutations that involve the $\mathrm{C}$-terminal residues which contain phosphorylation sites implicated in deactivation (Baylor and Burns, 1998). This implies that the normal mechanisms for shutting off WT Rh* apparently also operate on G90D Rh*. Furthermore, it would seem that any continuous activation of the phototransduction cascade by G90D might become quenched with time, as reported in K296E mice. Although increased basal activity of G90D apoprotein has been found in vitro (Rao et al., 1994), in these G90D mice in vivo the opsin apparently holds 11-cis-retinal, as it forms a visual pigment with $\lambda_{\max }$ of $492 \mathrm{~nm}$ that is bleachable by light and can subserve photostimulation as demonstrated by the ERG responses in $(\mathrm{G}+/+, \mathrm{R}-/-)$ mice. Consequently, one might venture that thermal activity of G90D molecules provides a plausible mechanism by which G90D light adapts the rods. This remains to be demonstrated.

\section{Comparison with nightblindness from P23H rhodopsin degeneration}

The G90D phenotype is quite different from the nightblindness resulting from rod cell loss in more typical rhodopsin retinal degeneration. Human $\mathrm{P} 23 \mathrm{H}$ rhodopsin retinal degeneration (Berson et al., 1991) raises rod-mediated visual thresholds proportional to the loss of rhodopsin density (Kemp et al., 1992). P23H rhodopsin transgenic rats mimic this degeneration and show considerable, progressive photoreceptor loss over the first one-half year of life (Steinberg et al., 1996), accompanied by progressive loss of a-wave and b-wave sensitivities (Machida et al., 2000). $\mathrm{P} 23 \mathrm{H}$ line-1 rats as progressive $0.4-0.5 \mathrm{log}$ unit loss of a-wave threshold as the ONL was thinned by $35-50 \%$ between 4 and 15 weeks of age (Machida et al., 2000). By contrast, the $0.37 \mathrm{log}$ unit a-wave threshold elevation in $(\mathrm{G}+/-, \mathrm{R}+/-)$ mice occurred without rod cell loss or ROS shortening, and the $1.1 \mathrm{log}$ units elevation in $(\mathrm{G}+/+, \mathrm{R}+/-)$ mice was greatly disproportionate to the minimal rod changes in comparison to $\mathrm{P} 23 \mathrm{H}$ rhodopsin mutants.

\section{Relationship of constitutive activity to retinal degeneration}

Constitutive activity of some mutant rhodopsins is proposed as contributing to rod death and retinal degeneration (Fain and Lisman, 1993; Lisman and Fain, 1995). The difference between congenital "stationary" nightblindness and progressive degeneration of rod cells may depend on the degree of intrinsic activity. G90D pigment in $(\mathrm{G}+/-, \mathrm{R}+/-)$ retinas resulted in an equivalent bleach level that does not saturate the rods but lies within their physiological functional range and apparently is tolerated on a chronic basis without causing rod cell death.

Albino rats maintain a photostasis under a range of environmental lighting: that is, they regulate rhodopsin levels and maintain a consistent level of total daily photon catch (Penn and Williams, 1986). Retinal degeneration is an extreme response to severe over-stimulation of rods by light (Noell et al., 1966). For lower intensities of 3-800 lux, the rods change their outer segment length, alter their rate of pigment regeneration after bleach, and even diminish the rate of rhodopsin synthesis (Schremser and Williams, 1995). Although ROS length was unaffected in G90D mice, there was evidence for downregulation of rhodopsin expression by G90D, as if photostasis were operating on transgenic mice to reduce photon absorption. One photopic lux at the cornea gives $\sim 650 \mathrm{Rh}^{*} \operatorname{rod}^{-1} \mathrm{sec}^{-1}$ (Pugh, 1998). Thus the higher estimate of G90D endogenous light of $82 \mathrm{Rh}^{*} \mathrm{rod}^{-1} \mathrm{sec}^{-1}$ for $(\mathrm{G}+/-, \mathrm{R}+/-)$ is roughly equivalent to $\frac{1}{8}$ lux of environmental light, or $\frac{3}{5}$ lux for $(\mathrm{G}+/+, \mathrm{R}+/-)$, which is far below the typical illuminance range over which photostasis is observed experimentally. However, even these low levels in G90D mice are sufficient to change the operating characteristics of the rod photoreceptors, as evidenced by the ERG recordings. Thus, it remains a possibility that continuous exposure to this dim dark light, which is present from birth in G90D retinas, may have an effect on rhodopsin levels beyond that expected for intermittent low rates of isomerization.

The degree to which constitutive activity is a major component in retinal degeneration is a matter to explore further. Besides G90D (Sieving et al., 1995), the T94I (al-Jandal et al., 1999) and the A292E rhodopsin mutations (Dryja et al., 1993) are further counter-examples that show quite minimal degeneration, despite confirmed or presumed constitutive activity. A292E is one helical turn below the Lys-296 opsin Schiff's base, and like G90D, it introduces a negative charge that may interfere with the salt bridge (Dryja et al., 1993). A292E opsin activated transducin in vitro at a considerable rate even in the absence of 11-cis-retinal, consistent with constitutive activity. Transgenic mice have not yet been made for either T94I or A292E, but a prediction is that both mutants would generate low, tolerable levels of chronic activity in the rods. 


\section{REFERENCES}

Aho AC, Donner K, Hyden C, Larsen LO, Reuter T (1988) Low retinal noise in animals with low body temperature allows high visual sensitivity. Nature 334:348-350.

al-Jandal N, Farrar GJ, Kiang AS, Humphries MM, Bannon N, Findlay JB, Humphries P, Kenna PF (1999) A novel mutation within the rhodopsin gene (Thr-94-Ile) causing autosomal dominant congenital stationary night blindness. Hum Mutat 13:75-81.

Al-Ubaidi MR, Pittler SJ, Champagne MS, Triantafyllos JT, McGinnis JF, Baehr W (1990) Mouse rod opsin: gene structure and molecular basis of multiple transcripts. J Biol Chem 265:20563-20569.

Barlow HB (1988) The thermal limit to seeing. Nature 334:296-297.

Baylor DA, Burns ME (1998) Control of rhodopsin activity in vision. Eye 12:521-525.

Baylor DA, Nunn BJ, Schnapf JL (1984) The photocurrent, noise and spectral sensitivity of rods of the monkey Macaca fascicularis. J Physiol (Lond) 357:575-607.

Bech-Hansen NT, Naylor MJ, Maybaum TA, Sparkes RL, Koop B, Birch DG, Bergen AA, Prinsen CF, Polomeno RC, Gal A, Drack AV, Musarella MA, Jacobson SG, Young RS, Weleber RG (2000) Mutations in NYX, encoding the leucine-rich proteoglycan nyctalopin, cause $\mathrm{X}$-linked complete congenital stationary night blindness. Nat Genet 26:319-323.

Berson EL (1993) Retinitis pigmentosa. The Friedenwald lecture. Invest Ophthalmol Vis Sci 34:1659-1676.

Berson EL, Rosner B, Sandberg MA, Dryja TP (1991) Ocular findings in patients with autosomal dominant retinitis pigmentosa and a rhodopsin gene defect (Pro-23-His). Arch Ophthalmol 109:92-101.

Chen J, Makino CL, Peachey NS, Baylor DA, Simon MI (1995) Mechanisms of rhodopsin inactivation in vivo as revealed by a $\mathrm{COOH}$ terminal truncation mutant. Science 267:374-377.

Cone RA (1963) Quantum relations of the rat electroretinogram. J Gen Physiol 46:1267-1286.

Crescitelli F (1956) The nature of the lamprey visual pigment. J Gen Physiol 39:423-435.

Dartnall HJA (1953) The interpretation of spectral sensitivity curves. Br Med Bull 9:24-30.

Dawis SM (1981) Polynomial expressions of pigment nomograms. Vision Res 21:1427-1430.

Dowling J (1967) The site of visual adaptation. Science 155:273-279.

Dryja TP, Berson EL, Rao VR, Oprian DD (1993) Heterozygous missense mutation in the rhodopsin gene as a cause of congenital stationary nightblindness. Nat Genet 4:280-283.

Faber DS (1969) Analysis of slow transretinal potential in response to light. PhD thesis, State University of New York at Buffalo.

Fain GL, Lisman JE (1993) Photoreceptor degeneration in vitamin A deprivation and retinitis pigmentosa: the equivalent light hypothesis. Exp Eye Res 57:335-340.

Fulton AB, Manning KA, Baker BN, Schukar SE, Bailey CJ (1982) Dark-adapted sensitivity, rhodopsin content, and background adaptation in pcd/pcd mice. Invest Ophthalmol Vis Sci 22:386-393.

Gorgels TGMF, van Norren D (1992) Spectral transmittance of the rat lens. Vision Res 32:1509-1512.

Green DG, Kapousta-Bruneau NV (1999a) A dissection of the electroretinogram from the isolated rat retina with microelectrodes and drugs. Vis Neurosci 16:727-741.

Green DG, Kapousta-Bruneau NV (1999b) Electrophysiological properties of a new isolated rat retina preparation. Vision Res 39:2165-2177.

Green DG, Powers MK (1982) Mechanisms of light adaptation in rat retina. Vision Res 22:209-216.

Hecht S, Shlaer S, Pirenne M (1942) Energy, quanta, and vision. J Gen Physiol 25:819-840.

Huang PC, Gaitan AE, Hao Y, Petters RM, Wong F (1993) Cellular interactions implicated in the mechanism of photoreceptor degeneration in transgenic mice expressing a mutant rhodopsin gene. Proc Natl Acad Sci USA 90:8484-8488.

Humphries MM, Rancourt D, Farrar GJ, Kenna P, Hazel M, Bush RA, Sieving PA, Sheils DM, McNally N, Creighton P, Erven A, Boros A, Gulya K, Capecchi MR, Humphries P (1997) Retinopathy induced in mice by targeted disruption of the rhodopsin gene. Nat Genet $15: 216-219$.

Kaushal S, Khorana HG (1994) Structure and function in rhodopsin. 7. Point mutations associated with autosomal dominant retinitis pigmentosa. Biochemistry 33:6121-6128.

Kemp CM, Jacobson SG, Roman AJ, Sung C, Nathans J (1992) Abnormal rod dark adaptation in autosomal dominant retinitis pigmentosa with proline-23-histidine rhodopsin mutation. Am J Ophthalmol 113:165-174.

Knowles A, Dartnall HJA (1977) Spectroscopy of visual pigments. In: The eye (Davson H, ed), p 70. New York: Academic.

Kofuji P, Ceelen P, Zahs KR, Surbeck LW, Lester HA, Newman EA (2000) Genetic inactivation of an inwardly rectifying potassium channel (Kir4.1 subunit) in mice: phenotypic impact in retina. $\mathbf{J}$ Neurosci 20:5733-5740.
LaVail MM, Gorrin GM, Yasumura D, Matthes MT (1999) Increased susceptibility to constant light in $\mathrm{nr}$ and pcd mice with inherited retinal degenerations. Invest Ophthalmol Vis Sci 40:1020-1024.

Lem J, Applebury ML, Falk JD, Flannery JG, Simon M I (1991) Tissuespecific and developmental regulation of rod opsin chimeric genes in transgenic mice. Neuron 6:201-210.

Lem J, Krasnoperova NV, Calvert PD, Kosaras B, Cameron DA, Nicolo M, Makino CL, Sidman RL (1999) Morphological, physiological, and biochemical changes in rhodopsin knockout mice. Proc Natl Acad Sci USA 96:736-741.

Li T, Franson WK, Gordon JW, Berson EL, Dryja TP (1995) Constitutive activation of phototransduction by K296E opsin is not a cause of photoreceptor degeneration. Proc Natl Acad Sci USA 92:3551-3555.

Li T, Snyder WK, Dryja TP (1996) Transgenic mice carrying dominant rhodopsin mutations T17M or P347S: evidence that mutant rhodopsin may interfere with disc assembly. Invest Ophthalmol Vis Sci 37:S698.

Li Z-Y, Jacobson SG, Milam AH (1994) Autosomal dominant retinitis pigmentosa caused by the threonine-17-methionine rhodopsin mutation: retinal histopathology and immunocytochemistry. Exp Eye Res 58:397-408.

Lisman J, Fain G (1995) Support for the equivalent light hypothesis. Nat Med 1:1254-1255.

Lyubarsky AL, Pugh ENJ (1996) Recovery phase of the murine rod photoresponse reconstructed from electroretinographic recordings. J Neurosci 16:563-571.

Machida S, Kondo M, Jamison JA, Khan NW, Kononen LT, Sugawara T, Bush RA, Sieving PA (2000) P23H rhodopsin transgenic rat: correlation of retinal function with histopathology. Invest Ophthalmol Vis Sci 41:3200-3209.

MacKenzie D, Arendt A, Hargrave P, McDowell J, Molday RS (1984) Localization of binding sites for carboxyl terminal-specific antirhodopsin monoclonal antibodies using synthetic peptides. Biochemistry 23:6544-6549.

McNally N, Kenna P, Humphries MM, Hobson AH, Khan NW, Bush RA, Sieving PA, Humphries P, Farrar GJ (1999) Structural and functional rescue of murine rod photoreceptors by human rhodopsin transgene. Hum Mol Genet 8:1309-1312.

Milam AH, Li ZY, Fariss RN (1998) Histopathology of the human retina in retinitis pigmentosa. Prog Retin Eye Res 17:175-205.

Molday RS, MacKenzie D (1983) Monoclonal antibodies to rhodopsin: characterization, cross-reactivity, and application as structural probes. Biochemistry 22:653-660.

Naash MI, Hollyfield JG, Al-Ubaidi MR, Baehr W (1993) Simulation of human autosomal dominant retinitis pigmentosa in transgenic mice expressing a mutated murine opsin gene. Proc Natl Acad Sci USA 90:5499-5503.

Nathans J, Hogness DS (1984) Isolation and nucleotide sequence of the gene encoding human rhodopsin. Proc Natl Acad Sci USA 81:4851-4855.

Nikonov S, Lamb TD, Pugh ENJ (2000) The role of steady phosphodiesterase activity in the kinetics and sensitivity of the light-adapted salamander rod photoresponse. J Gen Physiol 116:795-824.

Noell WK, Walker VS, Kang BS, Berman S (1966) Retinal damage by light in rats. Invest Ophthalmol Vis Sci 5:450-473.

Olsson JE, Gordon JW, Pawlyk BS, Roof D, Hayes A, Molday RS, Mukai S, Cowley GS, Berson EL, Dryja TP (1992) Transgenic mice with a rhodopsin mutation (Pro23His): a mouse model of autosomal dominant retinitis pigmentosa. Neuron 9:815-830.

Penn JS, Williams TP (1986) Photostasis: regulation of daily photoncatch by rat retinas in response to various cyclic illuminances. Exp Eye Res 43:915-928.

Penn RD, Hagins WA (1969) Signal transmission along retinal rods and the origin of the electroretinogram a-wave. Nature 223:201-204.

Pugh E (1998) Appendix II: Homogeneous light-rearing environments, quantifying their illumination, and converting illuminance to rates of photoisomerization in rods. In: Photostasis and related phenomena. (Williams TP, Thistle AB, eds), pp 126-128. New York: Plenum.

Quiambao AB, Peachey NS, Mangini NJ, Röhlich P, Hollyfield JG, Al-Ubaidi MR (1997) A 221-bp fragment of the mouse opsin promoter directs expression specifically to the rod photoreceptors of transgenic mice. Vis Neurosci 14:617-625.

Rao VR, Cohen GB, Oprian DD (1994) Rhodopsin mutation G90D and a molecular mechanism for congenital night blindness. Nature 367:639-641.

Raport CJ, Lem J, Makino C, Chen CK, Fitch CL, Hobson A, Baylor D, Simon MI, Hurley JB (1994) Downregulation of cGMP phosphodiesterase induced by expression of GTPase-deficient cone transducin in mouse rod photoreceptors. Invest Ophthalmol Vis Sci 35:2932-2947.

Rieke F, Baylor DA (2000) Origin and functional impact of dark noise in retinal cones. Neuron 26:181-186.

Robinson PR, Cohen GB, Zhukovsky EA, Oprian DD (1992) Constitutively active mutants of rhodopsin. Neuron 9:719-725.

Robson JG, Frishman LJ (1995) Response linearity and kinetics of the cat retina: the bipolar cell component of the dark-adapted electroretinogram. Vis Neurosci 12:837-850. 
Sakmar TP, Franke RR, Khorana HG (1989) Glutamic acid-113 serves as the retinylidene Schiff base counterion in bovine rhodopsin. Proc Natl Acad Sci USA 86:8309-8313.

Schnapf JL, Nunn BJ, Meister M, Baylor DA (1990) Visual transduction in cones of the monkey Macaca fascicularis. J Physiol (Lond) [Erratum (1990) 431:757] 427:681-713.

Schremser JL, Williams TP (1995) Rod outer segment (ROS) renewal as a mechanism for adaptation to a new intensity environment. II. Rhodopsin synthesis and packing density. Exp Eye Res 61:25-32.

Sieving PA, Richards JE, Naarendorp F, Bingham EL, Scott K, Alpern M (1995) Dark-light: model for nightblindness from the human rhodopsin Gly90 $\rightarrow$ Asp mutation. Proc Natl Acad Sci USA 92:880-884.

Steinberg RH, Flannery JG, Naash MI, Oh P, Matthes MT, Yasumura D, Lau-Villacorte C, Chen J, LaVail MM (1996) Transgenic rat models of inherited retinal degeneration caused by mutant opsin genes. Invest Ophthalmol Vis Sci [Suppl] 37:S698.

Sugawara T, Sieving PA, Bush RA (2000) Quantitative relationship of the scotopic and photopic ERG to photoreceptor cell loss in light damaged rat. Exp Eye Res 70:693-705.

Sung C-H, Makino C, Baylor D, Nathans J (1994) A rhodopsin gene mutation responsible for autosomal dominant retinitis pigmentosa results in a protein that is defective in localization to the photoreceptor outer segment. J Neurosci 14:5818-5833.

Toda K, Bush RA, Humphries P, Sieving PA (1999) The electroretinogram of the rhodopsin knockout mouse. Vis Neurosci 16:391-398.
Williams TP, Henrich S, Reiser M (1998) Effect of eye closures and openings on photostasis in albino rats. Invest Ophthalmol Vis Sci 39:603-609.

Wyszecki G, Stiles WS (1982) Color science: concepts and methods, quantitative data and formulae, Ed 2. New York: Wiley.

Xu J, Dodd RL, Makino CL, Simon MI, Baylor DA, Chen J (1997) Prolonged photoresponses in transgenic mouse rods lacking arrestin. Nature 389:505-509.

Zack DJ, Bennett J, Wang Y, Davenport C, Klaunberg B, Gearhart J, Nathans J (1991) Unusual topography of bovine rhodopsin promoterlacZ fusion gene expression in transgenic mouse retinas. Neuron 6:187-199.

Zvyaga TA, Min KC, Beck M, Sakmar TP (1993) Movement of the retinylidene Schiff base counterion in rhodopsin by one helix turn reverses the $\mathrm{pH}$ dependence of the metarhodopsin I to metarhodopsin II transition. J Biol Chem 268:4661-4667.

Zvyaga TA, Fahmy K, Sakmar TP (1994) Characterization of rhodopsin-transducin interaction: a mutant rhodopsin photoproduct with a protonated Schiff base activates transducin. Biochemistry 33:9753-9761.

Zvyaga TA, Fahmy K, Siebert F, Sakmar TP (1996) Characterization of the mutant visual pigment responsible for congenital night blindness: a biochemical and Fourier-transform infrared spectroscopy study. Biochemistry 35:7536-7545. 